\title{
Assessing bone mineralisation in children with chronic kidney disease: what clinical and research tools are available?
}

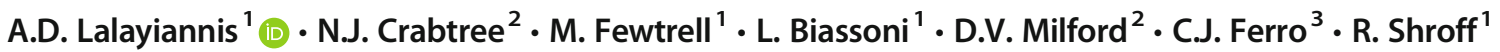

Received: 27 February 2019 /Revised: 19 April 2019 / Accepted: 26 April 2019/Published online: 25 June 2019

(C) The Author(s) 2019

\begin{abstract}
Mineral and bone disorder in chronic kidney disease (CKD-MBD) is a triad of biochemical imbalances of calcium, phosphate, parathyroid hormone and vitamin D, bone abnormalities and soft tissue calcification. Maintaining optimal bone health in children with CKD is important to prevent long-term complications, such as fractures, to optimise growth and possibly also to prevent extra-osseous calcification, especially vascular calcification. In this review, we discuss normal bone mineralisation, the pathophysiology of dysregulated homeostasis leading to mineralisation defects in CKD and its clinical consequences. Bone mineralisation is best assessed on bone histology and histomorphometry, but given the rarity with which this is performed, we present an overview of the tools available to clinicians to assess bone mineral density, including serum biomarkers and imaging such as dual-energy X-ray absorptiometry and peripheral quantitative computed tomography. We discuss key studies that have used these techniques, their advantages and disadvantages in childhood CKD and their relationship to biomarkers and bone histomorphometry. Finally, we present recommendations from relevant guidelines-Kidney Disease Improving Global Outcomes and the International Society of Clinical Densitometry — on the use of imaging, biomarkers and bone biopsy in assessing bone mineral density. Given low-level evidence from most paediatric studies, bone imaging and histology remain largely research tools, and current clinical management is guided by serum calcium, phosphate, PTH, vitamin D and alkaline phosphatase levels only.
\end{abstract}

Keywords Chronic kidney disease (CKD) $\cdot$ Dual-energy X-ray absorptiometry (DXA) $\cdot$ Peripheral quantitative CT (pQCT) $\cdot$ Bone biopsy $\cdot$ Bone mineralisation

\section{Introduction}

There is a growing awareness that mineral dysregulation in chronic kidney disease (CKD) is closely linked to abnormal bone pathology, and that this in turn, may potentially lead to extra-skeletal calcification. The KDIGO (Kidney Disease Improving Global Outcomes) have proposed the broad and

A.D. Lalayiannis

alex.lalayiannis@nhs.net

1 Nephrology Department Great Ormond St. Hospital for Children NHS Foundation Trust and University College London Institute of Child Health, London, UK

2 Birmingham Women's and Children's NHS Foundation Trust, Birmingham, UK

3 University Hospitals Birmingham NHS Foundation Trust, Birmingham, UK encompassing term chronic kidney disease-mineral and bone disorder (CKD-MBD) to describe this clinical entity [1]. MBD is the triad of biochemical abnormalities (of calcium, phosphate, parathyroid hormone (PTH) and 1,25-dihydroxyvitamin D), bone abnormalities (short stature, reduced mineralisation and increased risk of fractures) and extra-skeletal calcification $[2,3]$. Mineral dysregulation, leading to bone demineralisation, plays a causal role in increased bone pain, deformities and fracture risk in childhood CKD $[4,5]$.

Assessing bone health should be a key element in the clinical assessment of children with CKD, but the tools available to clinicians are not well researched and have many shortcomings. A detailed assessment of bone health and bone mineralisation in particular requires a combination of biochemical measures, imaging techniques and in some instances, bone biopsy. However, serum biomarkers may not be reflective of the true state of bone turnover or mineralisation and imaging techniques have several 
limitations and are not widely available. Bone biopsies are considered to be highly invasive and rarely performed in children.

In this review, we focus on the techniques available to the clinician to assess bone mineralisation by imaging methods, histology and biomarker studies. We examine their utility in the clinical setting and discuss relevant recommendations from international guidelines. Although bone mineralisation is best assessed by bone histomorphometry [6,7], radiological techniques are also used to assess bone mineral density (BMD) as a proxy in clinical practice and some studies. Given the low level of evidence from most clinical studies, these techniques are largely reserved for research, and current clinical management is guided by serum calcium, phosphate, PTH, vitamin D and alkaline phosphatase levels only.

\section{Normal bone mineralisation in the growing skeleton}

Bone development involves a process of organic matrix formation (osteoid), that is mineralised to form bone, and finally undergoes remodelling by resorption and reformation, old bone being replaced continuously by new bone (Figs. 1a and b) $[8,9]$. Remodelling of bone is controlled by osteoblasts and osteoclasts. Osteoblasts secrete procollagen during bone formation, and the end peptides are cleaved off during matrix formation to produce type 1 collagen. This structure serves as a scaffold around which mineralisation occurs [10]. Phosphates are released locally from the matrix vesicles in the osteoid. Calcium from the extracellular compartment then forms hydroxyapatite with the phosphates [11]. These crystals are also comprised of small amounts of sodium, magnesium and carbonate [12]. When the newly formed crystals are no longer soluble, they deposit in the form of hydroxyapatite in the vesicles. If there is sufficient phosphate and calcium available, hydroxyapatite formation continues to fill the spaces between the collagen fibres [13]. New bone formation happens by modelling and longitudinal growth at the growth plates by chondrocytes which are located between the epiphyses and metaphyses of long bones. The growth plates gradually move further away from the bone centre, producing elongation of the bone [14, 15]. Growth hormone is key in this process by driving the differentiation of chondrocytes to osteogenic cells, increasing cellular proliferation, increasing insulin-like growth factor 1 (IGF1) that stimulates the expansion of the chondrocytes and increasing deposition of type 1 collagen leading to further bone growth [14].

Bone mass, on the other hand, depends on the balance between bone resorption and formation. Bone modelling produces growth of the skeleton and changes in bone shape in response to mechanical forces [16]. This is the predominant driving force in early life. Remodelling renews bone and maintains mineral homeostasis. It repairs bone damage by resorbing old bone and forming new bone. In the growing skeleton, remodelling occurs very rapidly with a positive balance to account for mineral deposition and skeletal growth $[17,18]$. Both phases of bone metabolism-modelling and remodelling - are crucial in order to maintain good bone strength and prevent fractures.

\section{Calcium requirements for normal bone mineralisation}

Peak bone mass (PBM) is defined as 'the amount of bone gained by the time a stable skeletal steady state has been attained during adulthood' [19]. This incorporates and influences bone strength, which is derived from the structural properties provided by mass, density, microarchitecture and geometry of the bone. In a prospective study of 125 healthy girls over 8 years, girls who sustained at least one fracture ( $n=42$, cumulative incidence $46.6 \%$ ) were more likely to have lower bone mass by DXA [20]. The US National Osteoporosis Foundation position statement on peak bone mass development gives high-level evidence for physical activity and calcium intake on bone accretion, especially during late childhood and peripubertal years [19]. Normal bone mass accrual during growth is extremely important in preventing fractures in later life [19]. This is not surprising given that the mineral composition of bone accounts for two-thirds of its dry weight [12].

The timing of PBM accrual varies between the sexes and by the skeletal site. The Saskatchewan Paediatric Bone Mineral Accrual Study followed 164 children aged 8-14 years into their early 30s with dietary information and whole body DXA scans $[21,22]$. They showed that peak height velocity (PHV) was reached by 11.8 and 13.5 years for females and males, respectively, but PBM (highest BMC by total body DXA) was attained 7 years later. Bone development in terms of growth and length stopped around 5 years after PHV, followed by a plateau of bone mineralisation 2 years later (18.8 and 20.5 years for females and males respectively). However, at the lumbar spine and hips, in particular, PBM was achieved 5 years after PHV [22]. Previous cross-sectional studies had suggested that PBM is achieved even later than this. Recker et al. showed that in 156 healthy adult women, the mineral accrual stopped by 28.3 to 29.5 years of age [23]. Lin et al., studying 300 healthy females aged 6 to 32 years, found that bone mineral content (BMC) was highest in this cohort in the early twenties $(23.0 \pm$ 1.4 years), but increases in BMC were seen into the early thirties [24]. In summary, approximately $25 \%$ of PBM is formed around the 2-year interval of PHV which happens 


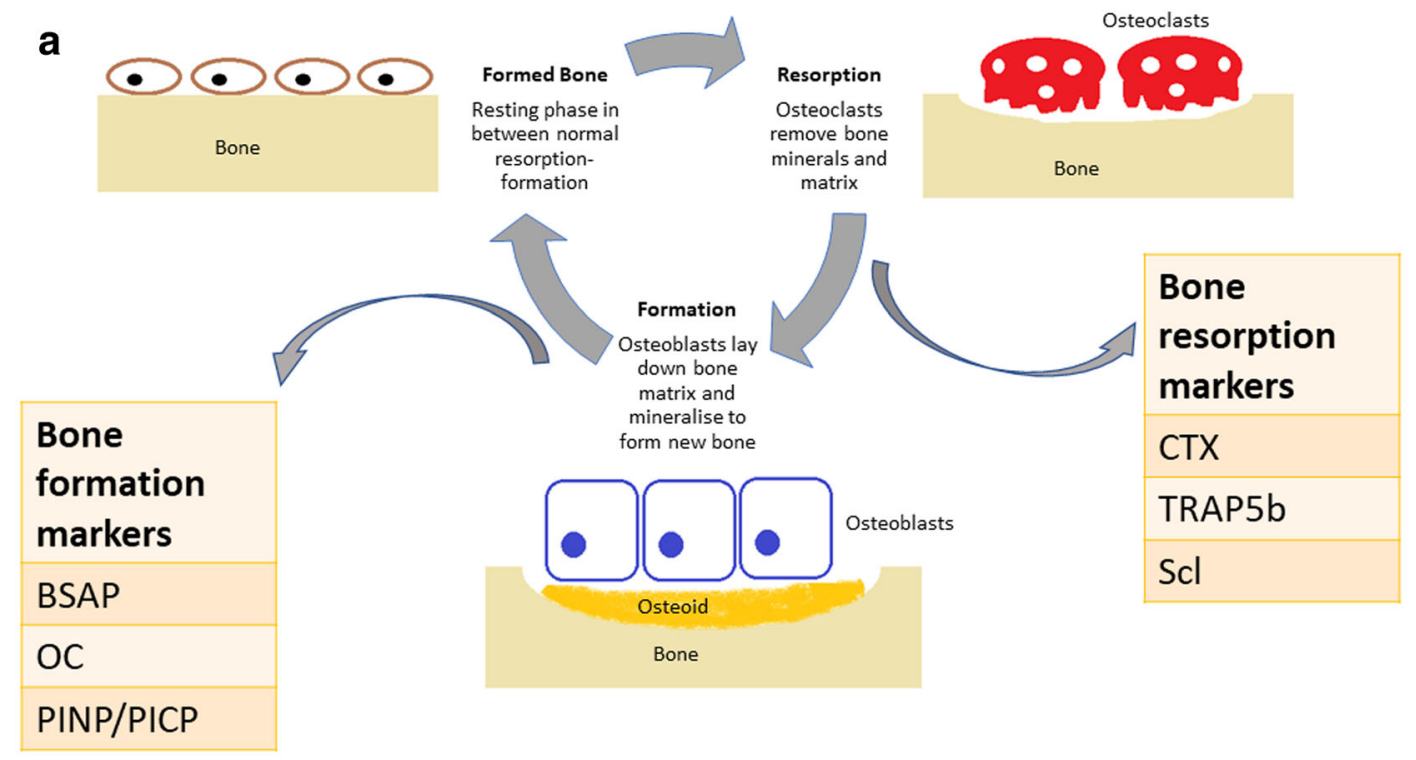

b

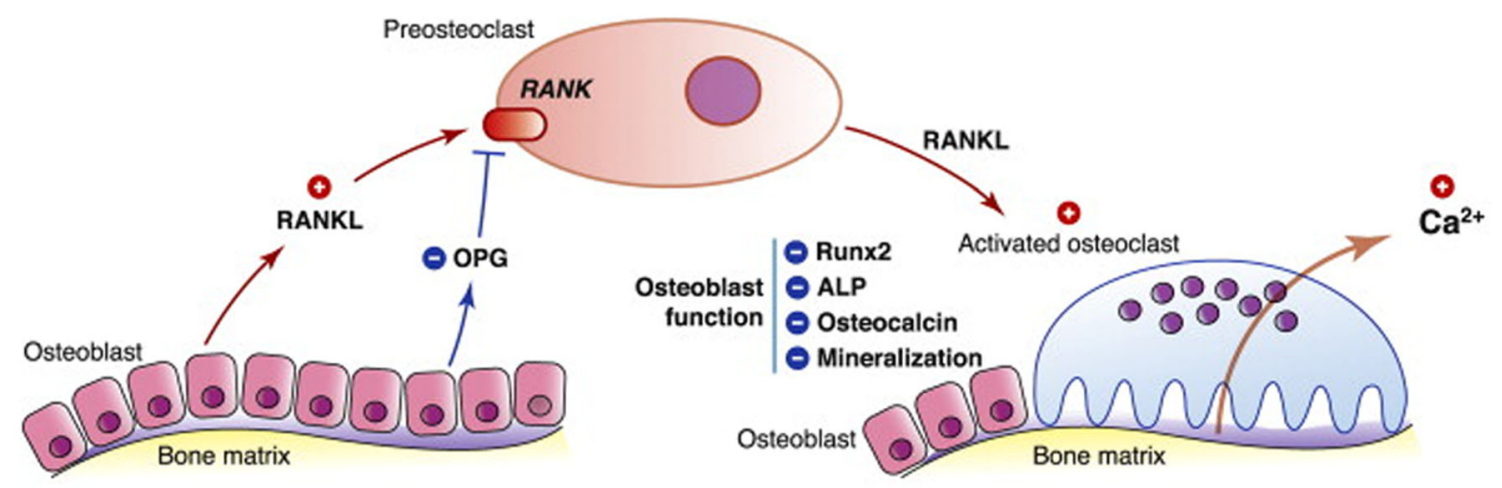

Fig. 1 a Remodelling of bone is controlled by osteoblasts and osteoclasts. Bone formation happens through organic matrix formation (osteoid), that gets mineralised to form bone, and finally undergoes remodelling by resorption and reformation. Calcium and phosphate form hydroxyapatite that deposits in the extracellular compartment, between collagen fibres. Osteoclasts are responsible for bone resorption, removing bone minerals and matrix. Certain biochemical markers reflect bone turnover and bone cell activity. Bone regulators can be grouped broadly into bone turnover factors (e.g. PTH, sclerostin) and bone cell activity indicators (bone formation, e.g. bone-specific alkaline phosphatase (BSAP), osteocalcin (OC), procollagen type I N propeptide (PINP), procollagen type I C propeptide (PICP); bone resorption, e.g. carboxyterminal cross-linking telopeptide of bone collagen (CTX), tartrate-resistant acid phosphatase (TRAP5b)). b Bone resorption is activated by the RANK-RANKL-OPG pathway, which regulates osteoclast differentiation and activation. Osteoclast precursors express RANK, which is activated by its ligand, RANKL, produced by osteoblasts and osteocytes. Osteoprotegerin (OPG), also a product of osteoblasts and osteocytes, is a decoy receptor for RANKL, neutralising the osteoclastic function activated by the RANKL-RANK complex. Thus, the RANKL/ OPG ratio is an important determinant of bone mass as it affects mineralisation, alkaline phosphatase, Runx 2 and osteocalcin which reflect osteoblast differentiation and bone formation rate. Figure adapted from Charoenphandhu et al. [117] in adolescence, but PBM is likely achieved by the end of the second or early third decade of life [22].

More than $99 \%$ of the calcium in the body is stored in the skeleton. The calcium content of the skeleton increases from $25 \mathrm{~g}$ at birth to around $1000 \mathrm{~g}$ in adulthood. This is the reason why the growing skeleton of children has a higher demand for calcium compared to adults [25]. Adequate dietary calcium intake during childhood and puberty is necessary for skeletal development and for attaining peak bone mass. Matkovic et al. published an aggregated report of 519 calcium balance studies performed on participants from birth to 30 years old. In every age group, calcium balance positively correlated with calcium intake from diet or supplements. The highest calcium requirement was in the first year of life $(503 \pm 91 \mathrm{mg} /$ day) and during pubertal growth $(396 \pm 164 \mathrm{mg} /$ day $)$, dropping thereafter to normal adult requirements (114 \pm $133 \mathrm{mg} /$ day) [25]. This implies higher intestinal calcium 
absorption and uptake by the growing skeleton in childhood and adolescence [25].

Studies have also associated oral dietary calcium intake with bone growth and mineral accrual in childhood [26, 27]. Bonjour et al. showed that daily consumption of a high calcium intake led to a greater increase in radial and femoral BMD in pre-pubescent girls [28]. Similarly, Cadogan et al. demonstrated that an increased intake of calcium (through milk) over 18 months resulted in a significant increase in BMD (9.6\% vs $8.5 \%, p=0.017)$ and BMC $(27.0 \%$ vs $24.1 \%, p=0.009)$ by DXA in 8212 year-old girls [29]. A randomised trial of 354 adolescent girls showed that increased calcium intake translated into significantly higher radial and total body BMD on DXA scan over the 7-year follow-up [30]. Abrams et al. using a calcium isotope technique demonstrated that increased dietary calcium absorption was the main driver of net calcium retention in infants and adolescents [31, 32]. The higher calcium requirements in children are also reflected in higher normal values for serum total calcium in children, particularly during periods of active growth in infancy, and reach adult levels by 5 years of age. The (US) National Osteoporosis Foundation's position statement review found that $90 \%$ of randomised control trials using calcium supplement pills showed a statistically significant effect on BMD and/or BMC accrual. This was especially seen in children with a lower calcium intake at baseline [19]. As bone mineral accrual in infancy, childhood and adolescence is closely linked with calcium intake and particularly oral calcium absorption [26, 27], any condition which disrupts this mechanism may lead to poor mineralisation [19].

\section{Abnormal bone mineralisation in CKD}

As the glomerular filtration rate reduces, phosphate excretion is impaired [33]. The reduced 1-alpha-hydroxylation of 25hydroxyvitamin $\mathrm{D}$ from the failing kidneys leads to reduced intestinal absorption of calcium and results in hypocalcaemia. Hypocalcaemia stimulates increased PTH production by the parathyroid glands and elevated phosphate levels stimulate fibroblast growth factor 23 (FGF23) secretion by osteocytes (Fig. 2) [34-36]. These compensatory pathways aim to increase phosphaturia and mobilise calcium out of its reservoir in the bone. PTH causes increased phosphaturia by acting on the renal phosphate sodium co-transporter and increases bone resorption [37], releasing calcium, which affects overall bone mineralisation [38-40]. FGF23 may also directly inhibit Wnt signalling pathways which are needed in bone mineralisation [41]. This high resorption state and demineralisation leads to an overall degradation of bone architecture, decreased BMD and increased fracture risk $[10,42]$.

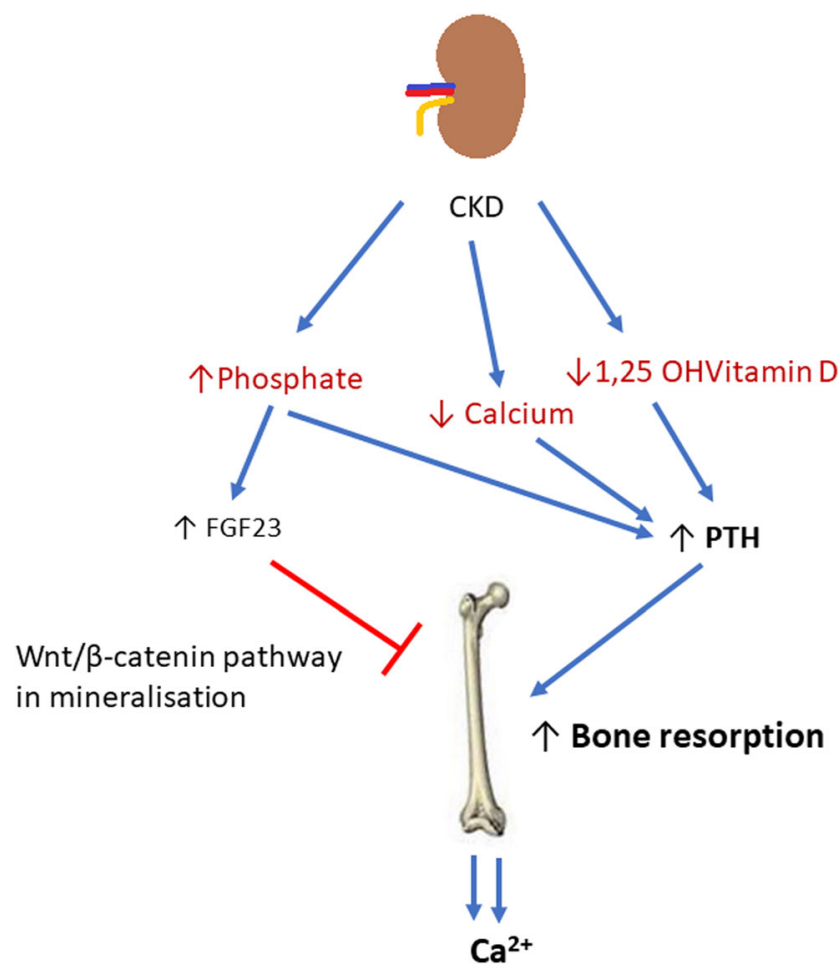

Fig. 2 In chronic kidney disease (CKD), hypocalcaemia, low 1,25 OH vitamin D levels and hyperphosphataemia develop. In an attempt to increase phosphaturia, and thus decrease serum phosphate levels, FGF23 production increases. Raised FGF23 may directly inhibit Wnt signalling pathways which are needed in bone mineralisation. Low $1,25 \mathrm{OHVitD}$ and low serum calcium lead to increased PTH production. This in turn causes increased bone turnover with the aim of restoring normocalcaemia, by mobilising calcium out of bone. The reduced production of active vitamin $\mathrm{D}$ from the kidneys perpetuates hypocalcaemia further fuelling this cycle. This demineralisation affects bone quality as a whole leading to an increased risk of fractures and decreased bone strength

\section{The burden of MBD in childhood CKD and the resulting fracture risk}

Chronic kidney disease affects bone modelling, remodelling and growth. Poorly controlled CKD leads to reduced bone mass accrual and accelerated bone loss. These alterations occur early in the course of CKD [43] but the entire and complete processes by which these abnormalities of skeletal mineralisation occur are not entirely clear [44]. Bone strength is determined by the bone mass and bone quality. It is affected by many factors including sex hormones, BMD, microarchitectural organisation, geometry and size. Cortical thickness and mineralisation are major contributors to overall bone strength $[45,46]$. CKD in childhood affects mineral homeostasis and the normal process of mineral accrual and deposition in the bone, thereby affecting bone mass, architecture and strength $[2,15]$.

Children with CKD are reported to have bone pain, limb deformities, short stature and a three-fold higher fracture incidence compared to their healthy peers [43, 47]. Borzych et al., using the clinical registry of the International Paediatric 
Peritoneal Dialysis Network (IPPN), showed that clinical symptoms or radiological signs of bone disease were present in $15 \%$ of 890 children and adolescents. These included radiological signs of renal rickets and osteopenia but also limb deformities and pain [33]. Fifty percent of children with CKD will not attain their genetically pre-determined height and remain significantly shorter [48].

The CKiD study (CKD in Children) has recently evaluated the burden of fractures in a large cohort of children. The reported fracture rates of 395/10,000 person-years for males and $323 / 10,000$ person-years for females were 2.4- and 3-fold higher, respectively, than gender-specific rates of 162/10,000 person-years and 103/10,000 person-years reported in a large population-based study of fracture epidemiology in healthy children and adolescents [38], and exceeding those reported in over 12,000 adult haemodialysis patients [38, 49]. The independently linked factors to higher fracture rates were baseline walking difficulty, Tanner stages of pubertal development 4-5, greater height $Z$-score, higher PTH levels and competitive sports participation. The only possible protective factor was phosphate binder use which afforded a $63 \%$ lower fracture risk; of note, $82 \%$ of patients in this study were on calcium-based phosphate binders, suggesting that improved phosphate control or the calcium absorption from the binder may afford some protective benefit $[38,43]$.

Lower BMD measured by peripheral quantitative computed tomography (pQCT) was identified as a significant predictor of fracture risk in a study of 170 children and young people up to 21 years old in CKD stages 2-5 and on dialysis. Lower serum calcium levels were independently associated with lower cortical volumetric BMD Z-scores. Over a 1-year follow-up in 89 children, a change in the cortical BMD $Z$-score positively correlated with baseline calcium $(p=0.008)$ and increase in calcium $(p=0.002)$ levels, particularly in growing children. Of these participants, $6.5 \%$ suffered some form of fracture during the study's 1-year follow-up (incidence 556/10,000 person-years). Notably, lower cortical BMD Z-score predicted future fractures: the hazard ratio for fractures was 1.75 (95\% CI 1.15-2.67; $p=0.009$ ) per SD decrease in baseline BMD. The fracture sites were the clavicle, tibia, foot, toes and radius. These fractures were sustained in low-impact traumas, such as exercise and falls. Independent risk factors attributed to fracture risk were any period of rapid growth in adolescence, lower calcium and vitamin D $(25(\mathrm{OH}) \mathrm{D})$ levels as well as a higher PTH at baseline. All were associated with lower cortical BMD scores [43].

The cumulative burden of MBD that develops during the pre-transplant period may be further exacerbated after transplantation. Children who have received any solid-organ transplant had a 6-fold higher incidence of fractures overall, but particularly vertebral fractures (160-fold) compared to healthy peers in a 5-year follow-up period $[50,51]$. Interestingly, a reduced lumbar BMD $Z$-score was observed in $17 \%$ of the participants at the time of transplantation [51]. Abnormalities in mineral metabolism also persist after transplantation; in a registry study of 1237 European children, 19\% had hypocalcaemia and $40 \%$ had a high PTH 3 years after transplantation (interquartile range 1.1-6.2 years) [50].

Mineral and bone disorder in childhood has long-lasting consequences into adulthood. A study of 249 young adults with the onset of end-stage renal failure pre-adolescence and followed into adulthood showed that $37 \%$ had symptoms of bone disease (deformities, bone pain, aseptic bone necrosis and atraumatic fractures), $18 \%$ were disabled by bone disease and $61 \%$ had severe growth restriction $[47,52]$. The United States Renal Data System reports that the relative risk of hip fracture was highest in young adults $(<45$ years old $)$ on haemodialysis, and hip fractures were associated with a more than 4-fold increase in mortality in dialysis patients compared to healthy age-matched peers [53-55].

\section{Techniques for assessing bone health}

Assessing bone health with a view to predicting and preventing fractures in children with CKD is challenging. Examining bone turnover, density and mineralisation in a non-invasive way that does not involve radiation are not possible. The current tools available for assessing bone turnover and density include bone histomorphometry, blood biomarkers and imaging techniques. We discuss these in turn.

\section{Bone biopsy}

Bone biopsy is considered the gold standard for bone assessment and allows assessment of the dynamic process of bone formation and resorption. The histologic findings are categorised in terms of bone turnover, mineralisation and volume (the 'TMV' classification) [56]. Bone biopsy is an invasive procedure and only a handful of adult and paediatric nephrology centres around the world perform this in clinical practice or for research purposes. The procedure requires an anaesthetic and dosing with tetracycline, which has UV fluorescence properties, at two different time intervals to 'label' the bone for assessment of the dynamic features of bone formation [57].

A review of five bone biopsy studies, performed in a total of 172 children on HD or PD, showed that $14-37 \%$ showed normal bone histology, with $22-43 \%$ showing low bone turnover. High PTH levels were able to identify high bone turnover states, but lower PTH levels were not able to distinguish between low and normal bone turnover [58]. A detailed discussion of bone histomorphometry studies and correlations with biomarkers is presented in the section below. 


\section{Serum biomarkers of bone formation and resorption}

Regulators of bone mineralisation and turnover can be measured in the blood or urine and reflect the metabolic activity of bone cells (Fig. 1b). They are usually grouped into:

i. Bone formation markers: Bone-specific alkaline phosphatase (BSAP), osteocalcin (OC), procollagen type I N propeptide (PINP), procollagen type I C propeptide (PICP). These markers are products of osteoblast metabolism and activity and reflect the production of type 1 collagen, the structure that serves as a scaffold around which mineralisation occurs [10], and accounts for more than $90 \%$ of the organic component of the bone matrix [12]. BSAP reflects bone formation rate [59]. In healthy children, BSAP is associated with age, and gender [60], increasing at the start of puberty, associated with height velocity and higher in boys [60].

ii. Bone resorption markers: Carboxyterminal cross-linking telopeptide of bone collagen (CTX) and tartrate-resistant acid phosphatase (TRAP5b). These markers are mainly by-products of type 1 collagen breakdown [10].

iii. Osteocytic markers: Phosphate-regulating gene with homologies to endopeptidases on the $\mathrm{X}$ chromosome (PHEX), dentin matrix protein-1 (DMP1), matrix extracellular phospho-glycoprotein (MEPE), sclerostin and FGF23 that can regulate both osteoblastic and osteoclastic activity [61].

All these biomarkers have been researched, drawing correlations with bone histology, imaging and fracture outcomes, but only PTH and BSAP are considered useful adjuncts to calcium and phosphate measurements in clinical practice.

In bone histomorphometry studies, serum PTH has been associated with both bone mineralisation and turnover (Table 1). However, PTH can remain within normal levels in the early stages of $\mathrm{CKD}$, despite bone biopsy studies showing that almost a third of children in CKD stage 2 have poor bone mineralisation [62, 63]. In 2010, Bakkaloglu et al. reviewed bone biopsies of 161 children on PD and identified mineralisation abnormalities in $48 \%$ of all patients. Abnormal mineralisation was found in $58 \%$ of participants with high bone turnover, $38 \%$ with normal turnover and $29 \%$ with low turnover. Serum PTH and alkaline phosphatase correlated with bone turnover (PTH: $r=0.61, p<0.01$; alkaline phosphatase: $r=0.51, p<0.01)$ and serum calcium was inversely related to mineralisation $(p<0.01)$ but not bone turnover. In any turnover state, higher PTH values and lower calcium values associated with abnormal mineralisation [62]. The authors demonstrated that when both PTH and alkaline phosphatase levels were within $2 \mathrm{xULN}$ normal bone turnover and normal mineralisation was seen [62].
Furthermore, PTH does not discriminate effectively between low- and high-turnover bone disease, in the ranges where most patients' PTH values are found (100-1000 ng/ L) [64]. Salusky et al., looking at biopsies of 55 children, found that serum calcium levels were higher in patients with adynamic bone or normal bone than in those with high PTH values. On the other hand, serum phosphate, alkaline phosphatase and PTH levels were higher in patients with osteitis fibrosa. The combination of a high serum PTH and normal calcium value was $85 \%$ sensitive and $100 \%$ specific for identifying patients with the high-turnover bone disease [65]. In general, all high-turnover disease was associated with high PTH levels (> 3 ULN upper limit normal) whereas adynamic bone disease and normal bone turnover were associated with lower PTH values, but the ability of PTH to distinguish between the two is not strong.

On clinical correlations, maintaining PTH within normal levels up to $2 \times$ ULN was associated with good growth [66]. In a study of 556 children aged 6-18 years with CKD (eGFR $10-60 \mathrm{~mL} / \mathrm{min} / 1.73 \mathrm{~m}^{2}$ ), BSAP SDS values decreased with declining eGFR and closely associated with PTH [67]. In patients treated with growth hormone, BSAP showed an increase after treatment. BSAP SDS were predictive of a prospective change in height SDS [67]. The International Paediatric Peritoneal Dialysis Network Registry that followed up nearly 900 children on PD found that clinical and radiological symptoms markedly increased when PTH exceeded $300 \mathrm{pg} / \mathrm{mL}$, the risk of hypercalcemia increased with levels below $100 \mathrm{pg} / \mathrm{mL}$ and time-averaged PTH concentrations above $500 \mathrm{pg} / \mathrm{mL}$ were associated with impaired longitudinal growth [33]. In a prospective study of 171 children with CKD, high PTH was independently associated with a decline in tibial cortical BMD on annual follow-up. [43]. A further study has also correlated higher BSAP and CTX levels were associated with lower cortical BMD [68].

In summary, no biomarker, individually or in combination, is sufficiently robust to diagnose bone mineralisation or turnover defects $[69,70]$. Furthermore, biomarkers vary depending on age, gender, pubertal stage, fasting status and circadian rhythms and assays are not always standardised [60, 71]. Larger paediatric studies that correlate bone biomarkers with the gold standard of bone histomorphometry as well as patient-level outcomes such as fractures are required.

\section{Imaging techniques}

\section{Dual-energy X-ray absorptiometry}

DXA is a tool that is used for evaluating bone density and assessing fracture risk in children and in adults. There is a growing body of literature on the use of DXA in different paediatric diseases [72]. 


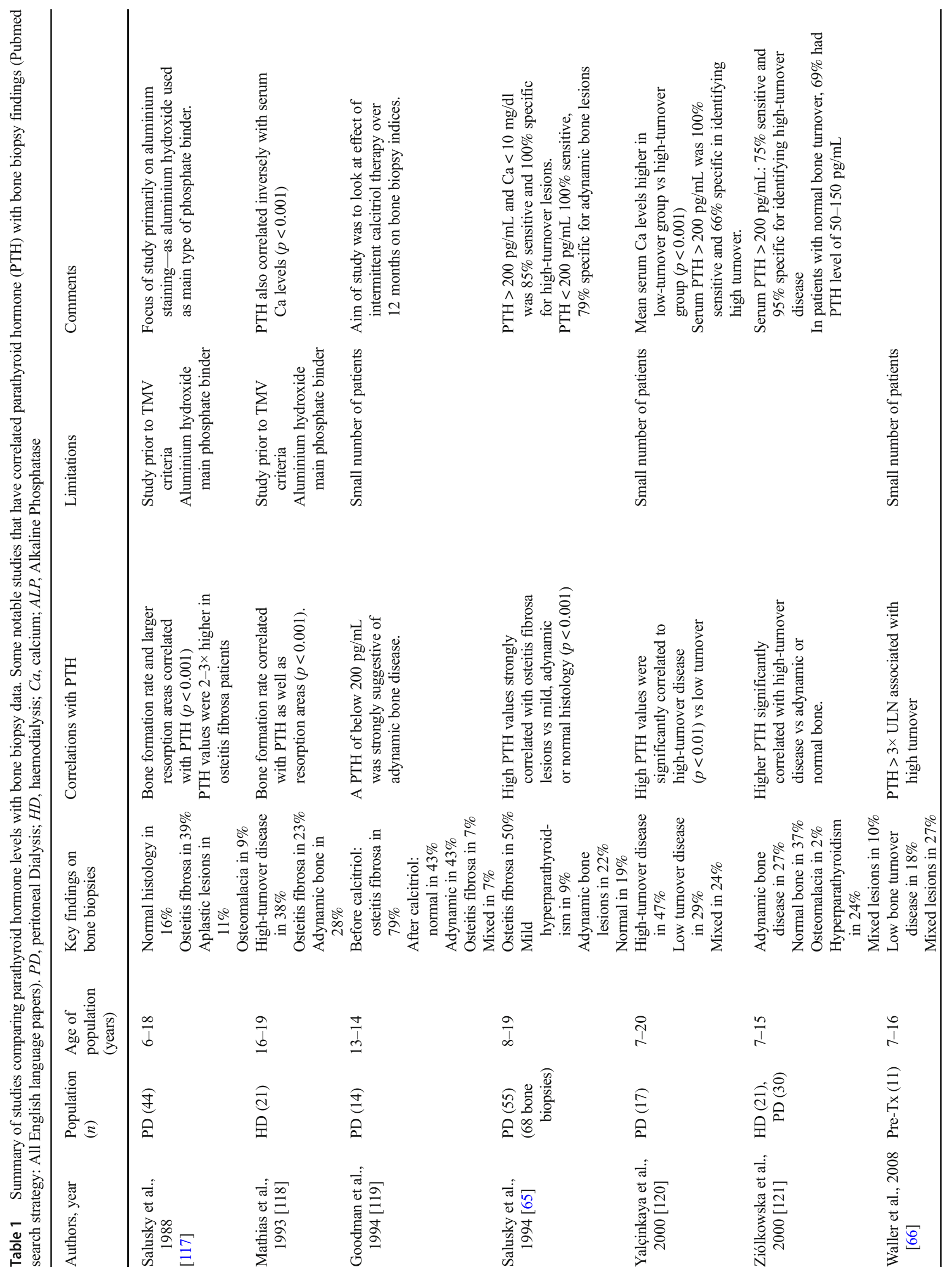




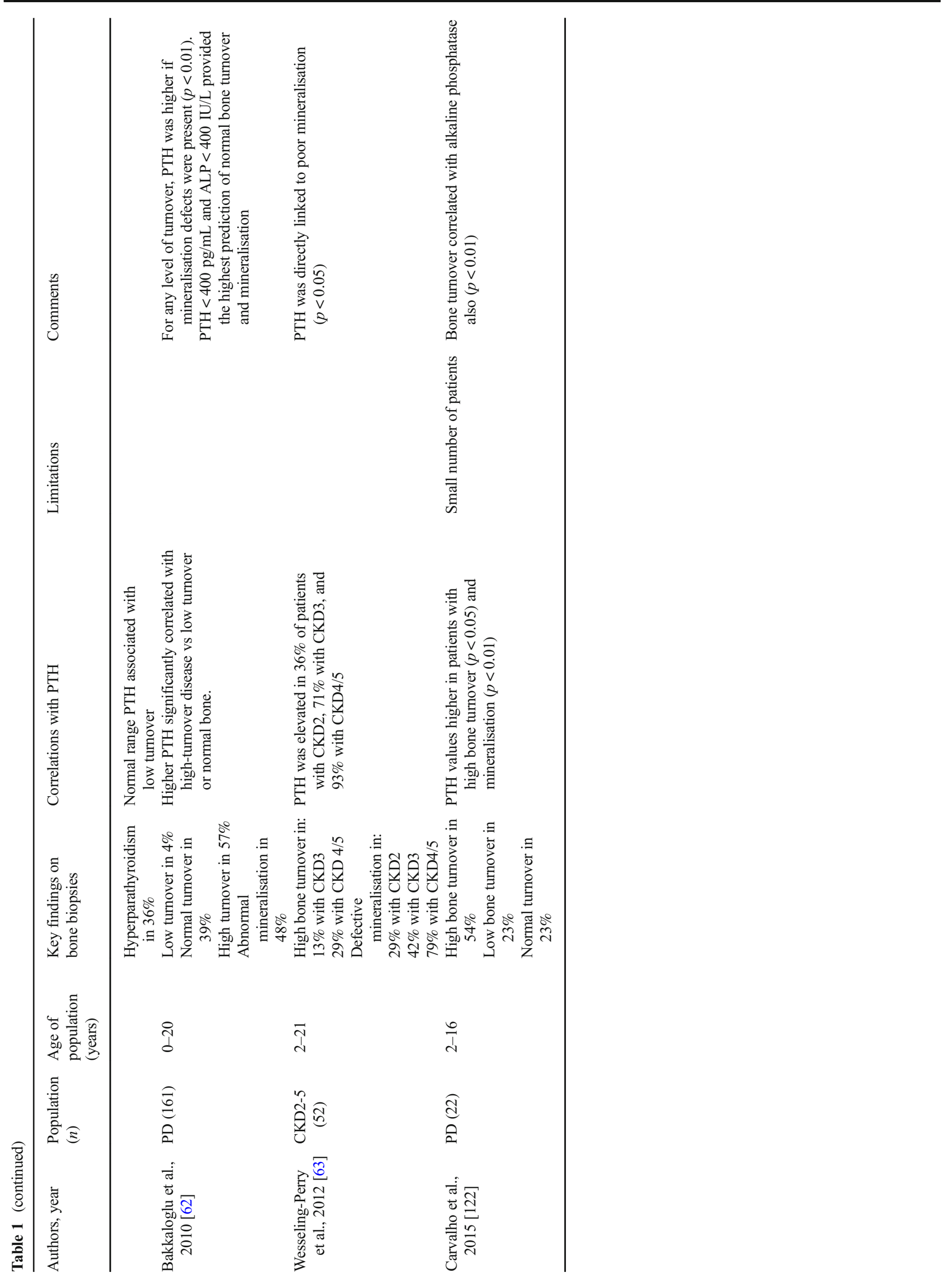


Principle A DXA scanner produces X-rays at 2 different energies, enabling the differentiation of soft tissue and bone [73]. Even at low levels of radiation (4-27 $\mu \mathrm{Sv})$ [74], DXA allows for measurement of bone mineral content (BMC) and projected bone area (BA), from which the areal BMD is calculated as $\mathrm{BMC} / \mathrm{BA}$.

Technique Measurements can be made at the spine, hip, forearm or whole body (WB, also described as the total body (TB)) [73]. Common sites in paediatric practice include lumbar spine (LS) and total body less head (TBLH) [75]. In children, LS DXA is particularly useful because vertebrae are mainly trabecular bone, and this site is readily influenced by pathologic processes, due to the rapid bone turnover [72]. The $\mathrm{L} 1$ to $\mathrm{L} 4$ region is recommended in the posterior-anterior direction. In adults, the recommended site is the femoral neck, as any possible aortic calcification can hinder interpretation of the lumbar region. Changes with growth and variations in development limit the use of the femoral site in pre-pubertal children. Good positioning of the patient by the operator is vital, but subsequently scanning lasts only a few seconds. Imaging can be blurred by motion artefact in very mobile children [76].

Information obtained DXA gives information on BMC (Table 2), measured in grams (g). This is produced automatically by the software and can be normalised for the child's height or bone area. BMD and content of mineral in a projected area of bone $\left(\mathrm{g} / \mathrm{cm}^{2}\right)$ are automatically derived and expressed in age, sex and ethnicity matched $Z$-scores [77]. If the score is below 2 standard deviation points $(-2 \mathrm{SD})$, then it indicates an abnormally low BMD for age [75]. Importantly,
BMD reflects density in a two-dimensional projection only. Therefore, it may be misleading in shorter children or those with delayed growth, as the projected bone area will be smaller. To overcome this problem, bone mineral apparent density (BMAD) is used to try and estimate the whole bone density in gram per cubic centimetre. A $Z$-score is also the preferred comparator for this measure (Fig. $3 a$ and b).

Reference data in healthy children Reference data for lumbar spine (L1-L4) BMAD and areal bone mineral density (areal BMD) in healthy children are available from 3598 healthy 4 to 20 year olds from 7 UK centres [78]. Studies providing reference curves from other datasets, mainly from the USA also exist [79-82]. DXA results should be adjusted for bone size (i.e. growth of the child), consistent with the 2013 International Society of Clinical Densitometry (ISCD) Paediatric official positions [76]. Equations to adjust DXA results for height $Z$-score are available [83]

Relative advantages and disadvantages Table 3 lists the main advantages and shortcomings of DXA in children. The greatest drawback of the DXA technique is that it assesses a three-dimensional structure (e.g. spinal vertebral body) as a two-dimensional image. Trabecular and cortical bone are superimposed, so studying the trabecular and cortical BMD separately cannot be done. Given that DXA measures areal BMD $\left(\mathrm{g} / \mathrm{cm}^{2}\right)$, it can underestimate volumetric BMD $\left(\mathrm{g} / \mathrm{cm}^{3}\right)$ in children with short stature [83] and overestimate BMD in a tall child [73]. Therefore, it is vital $Z$-scores are adjusted for poor growth especially in CKD [84]. Serial DXA scanning in growing children can be particularly challenging.
Table 2 Important terminology used when assessing bone. The terminology used when assessing bone. Important distinctions are made between BMC and BMD. The definitions of areal BMD and BMAD ensure that the limitations of DXA scanning in growth-stunted children with CKD are accounted for

\begin{tabular}{|c|c|}
\hline Terminology & Definition, units and description \\
\hline Bone mineral content (BMC) & $\begin{array}{l}\text { The amount of mineral found in an area of bone. Calcium is the predominant mineral found in bone. } \\
\text { Measured in grams (g) }\end{array}$ \\
\hline Bone mineral density (BMD) & $\begin{array}{l}\text { Mass of mineral per unit volume of bone } \\
\text { This reflects the ratio of bone mass to bone volume. } \\
\text { Referred to as cortBMD for the bone cortex and trabBMD for the trabecular bone } \\
\text { The ratio of BMC over bone size and thus expressed in } \mathrm{g} / \mathrm{cm}^{3} \text {. } \\
\text { BMD has been used interchangeably with areal BMD in the literature. }\end{array}$ \\
\hline $\begin{array}{l}\text { Areal bone mineral density } \\
\quad(\text { areal BMD) }\end{array}$ & $\begin{array}{l}\text { A term used within DXA reporting. } \\
\text { Mineral mass of the bone, divided by projection area of the X-rays (BMC/BA). The commonest parameter used in } \\
\text { assessing bone. } \\
\text { Represents a composite of bone size and mass } \\
\text { Expressed in } \mathrm{g} / \mathrm{cm}^{2}\end{array}$ \\
\hline $\begin{array}{l}\text { Bone mineral apparent density } \\
\text { (BMAD) }\end{array}$ & $\begin{array}{l}\text { BMAD is obtained by dividing the BMC by the estimated three-dimensional bone volume derived from its two } \\
\text { dimensional projected bone area. } \\
\text { This is done in children to account for growth and size in assessing bone density. } \\
\text { For example, the lumbar spine is assumed to be of cylindrical or cuboidal shape in children when calculating BMAD. }\end{array}$ \\
\hline
\end{tabular}


a

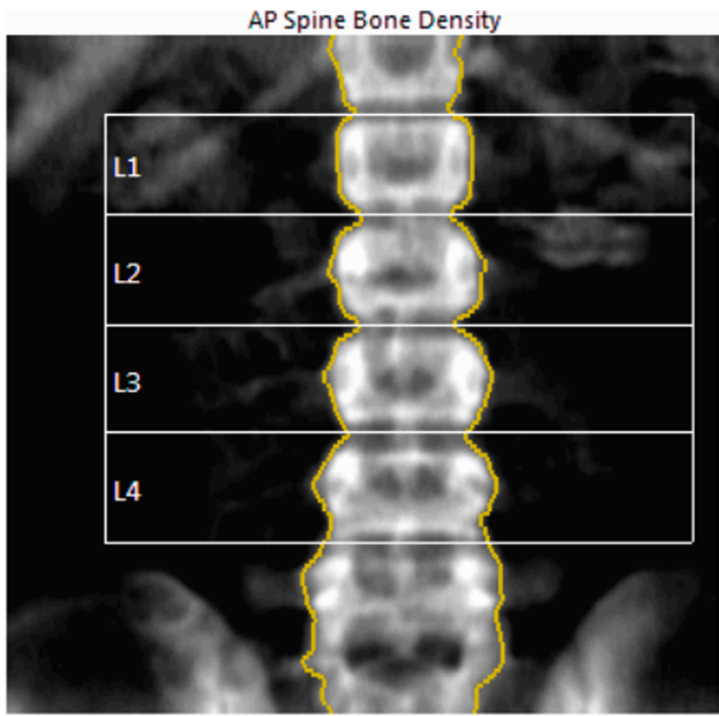

\section{Densitometry Ref: L1-L4 (BMD)}

BMD $\left(\mathrm{g} / \mathrm{cm}^{2}\right) \quad$ AM Z-score

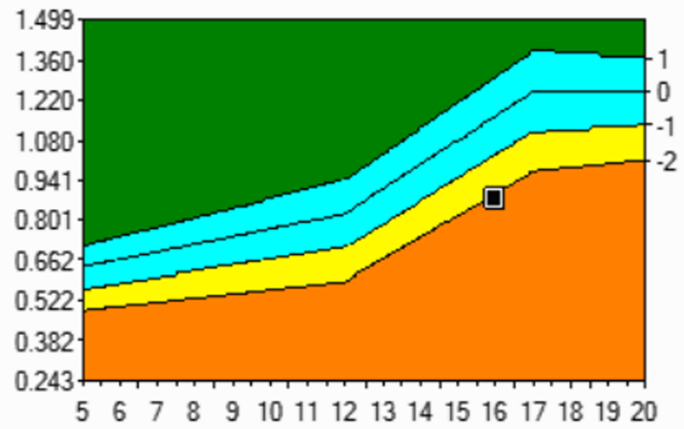

Age (years)

\begin{tabular}{|c|c|c|}
\hline Region & $\begin{array}{c}\mathrm{BMD}^{1} \\
\left(\mathrm{~g} / \mathrm{cm}^{2}\right)\end{array}$ & $\underset{\text { Z-score }}{\text { Age-Matched }}$ \\
\hline L1 & 0.825 & -2.0 \\
\hline L2 & 0.890 & -2.1 \\
\hline 13 & 0.912 & -2.0 \\
\hline$\llcorner 4$ & 0.863 & -2.3 \\
\hline L1-L4 & 0.874 & -2.1 \\
\hline L2-L4 & 0.887 & -2.2 \\
\hline
\end{tabular}

b

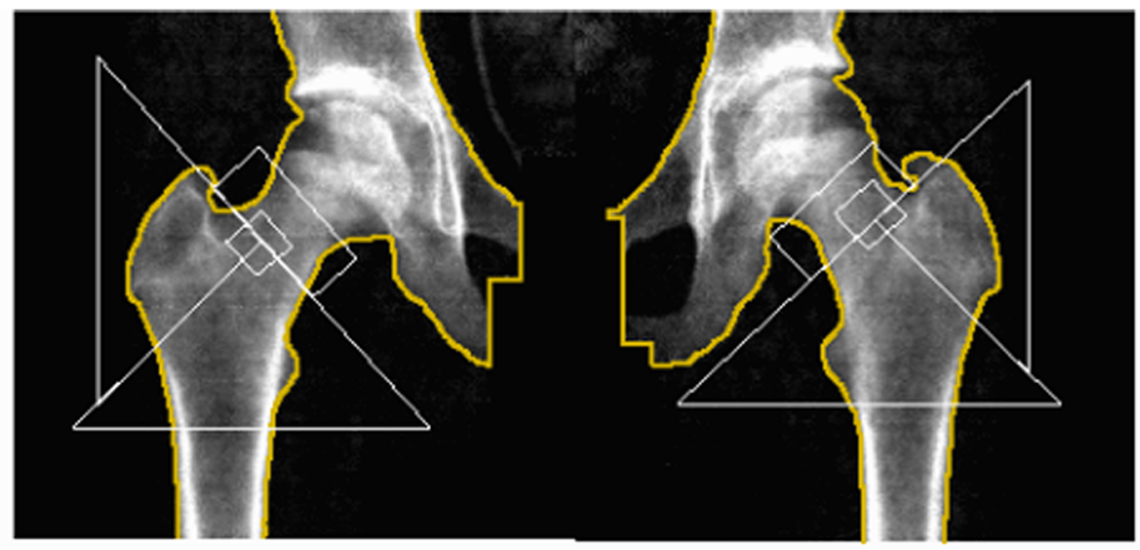

Image not for diagnosis

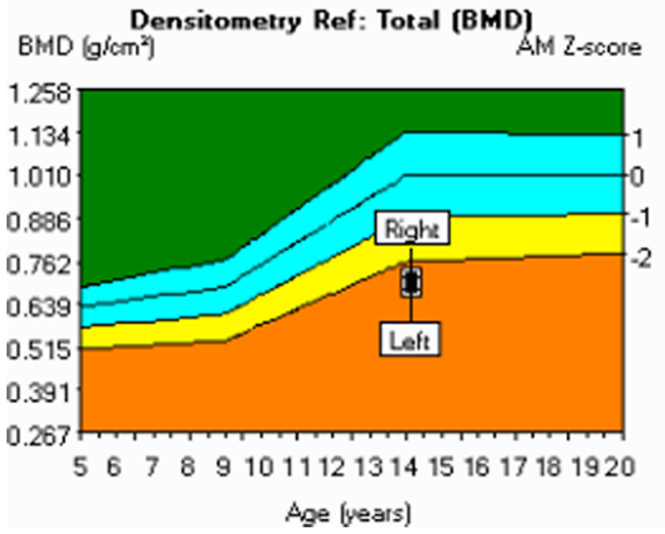

Fig. 3 a DXA images. This is an example of DXA imaging of the L1-4 spine of a 16-year-old male with chronic kidney disease. His mean L1-4 age-matched $Z$-score is -2.2 . However, when adjusted for his shorter height and poor growth, his BMAD $Z$-score is -0.8 (the BMAD value is obtained by adding the bone mineral content of the L1-L4 vertebrae and

\begin{tabular}{|c|c|c|c|}
\hline Region & $\underset{\left(g / \mathrm{cm}^{2}\right)}{\mathrm{BMD}}{ }^{1}$ & $\begin{array}{c}\text { Age-Matched } \\
(\%)\end{array}$ & Age-Matched $_{\text {2-score }}^{2,3}$ \\
\hline \multicolumn{4}{|l|}{ Neck } \\
\hline Left & 0.736 & 74 & -2.0 \\
\hline Right & 0.750 & 75 & -1.9 \\
\hline Mean & 0.743 & 74 & -2.0 \\
\hline Difference & 0.014 & 1 & 0.1 \\
\hline \multicolumn{4}{|l|}{ Total } \\
\hline Left & 0.686 & 68 & -2.6 \\
\hline Right & 0.709 & 70 & -2.4 \\
\hline Mean & 0.697 & 69 & -2.5 \\
\hline Difference & 0.023 & 2 & 0.2 \\
\hline
\end{tabular}

dividing by the total volume of the 4 vertebrae). $\mathbf{b}$ This is an example of a DXA image of both hips of a 14-year-old girl with chronic kidney disease on home nocturnal haemodialysis. Her mean age-matched $Z$-score for both hips is -2.5 
Table 3 Advantages and disadvantages of DXA imaging in children. The main advantages and disadvantages of DXA use in assessing bone in childhood CKD

\begin{tabular}{|c|c|}
\hline Advantages & Disadvantages \\
\hline Low radiation dose $(4-27 \mu \mathrm{Sv})$ & $\begin{array}{l}\text { Two-dimensional image - cannot distinguish } \\
\text { between cortical and trabecular bone }\end{array}$ \\
\hline Evaluation of body composition is possible & $\begin{array}{l}\text { Assesses areal BMD in } \mathrm{g} / \mathrm{cm}^{2} \text {, not density in } \\
\mathrm{g} / \mathrm{cm}^{3}\end{array}$ \\
\hline $\begin{array}{l}\text { Operator independent }- \text { serial follow-up and } \\
\text { standardisation across sites possible }\end{array}$ & $\begin{array}{l}\text { Underestimates BMD in children with poor } \\
\text { growth }\end{array}$ \\
\hline Widely available & $\begin{array}{l}\text { Does not evaluate the microarchitecture of } \\
\text { bone }\end{array}$ \\
\hline $\begin{array}{l}\text { Reference data standardised for age, sex, race and height } \\
\text { adjusted standard deviation scores (SDS) available }\end{array}$ & \\
\hline
\end{tabular}

Studies in CKD In adults with CKD, there is convincing evidence that lower BMD by DXA indicates an increased fracture risk. Yenchek et al. studied BMD by the femoral neck and total hip DXA in 2754 older adult individuals and showed that lower femoral neck BMD was associated with a higher fracture risk regardless of CKD status (hazard ratio $2.69,95 \%$ confidence intervals 1.96-3.69) [85]. In a longitudinal study by Iimori et al., adult participants with the lower total hip ( $p=$ $0.0006)$ or whole body $(p=0.006)$, BMD scores were more likely to have new fractures [86]. Two further cross-sectional studies by Nickolas et al. have shown associations between hip BMD and fracture history in adults with CKD $[87,88]$.

There are a few notable studies that have used DXA to determine BMD in the context of childhood CKD. Few explore associations with mineral dysregulation and fracture risk in children (Table 4). A study of 40 children both with pre-dialysis CKD and on dialysis showed that all had decreased BMD [89]. Waller et al. used lumbar DXA to assess BMD in a paediatric cohort of 64 patients with CKD, whilst studying biochemical markers and found that maintaining normal calcium, phosphate and PTH concentrations was associated with normal lumbar BMD and growth [90]. Griffin et al. used DXA and pQCT to assess BMD in 88 children with CKD stages 4-5 and compared the scores to 650 healthy participants aged 5-21 years old. They demonstrated that adjusting for lower height Z-scores in the CKD population results in increased BMD Z-scores in the lumbar spine and whole body DXA scans. This accounts for poor growth in this population, thereby avoiding overestimation of bone deficits [84].

Importantly, a study in 56 children after renal transplantation used both DXA and tibial pQCT to determine fracture risk [91] found that changes in DXA spine-BMD and tibial pQCT trabecular BMD correlated $(r=0.47, p<0.01)$ and changes in whole-body BMC $Z$-scores were associated with changes in tibia cortical area $Z$-scores $(r=0.52, p<0.001)$, but not changes in cortical BMD $Z$-scores. This suggests that the theoretical limitations of DXA in determining cortical and trabecular BMD may not be a major limitation in CKD patients after all.

\section{Quantitative computed tomography}

Principle QCT is a technique whereby CT images acquired are analysed by specific software to obtain quantitative measures such as volumetric bone mineral density (volumetric BMD) and BMC in any bone compartment [92]. Other measures acquired can be bone cross-sectional area or cortical thickness. Whole body CT scanners can be used, as well as specifically peripheral QCT scanners. The scanners used most commonly are the XCT 2000 and 3000 scanners (Stratec Medizintechnik, Pforzheim, Germany). They use a rotate/translate technology and can produce a 2D slice in around $1 \mathrm{~min}$ [74].

Technique pQCT has evolved from the quantitative CT techniques in the 1970 s and can now be done rapidly, accurately and peripherally. pQCT provides volumetric and density data in gram per cubic centimetre. It can distinguish between trabecular and cortical bone compartments independent of the size of the subject [73]. Due to this differentiation and because the trabecular bone is more metabolically active, pQCT offers a unique perspective when studying and assessing bone.

Performing the scan requires the placement of a reference line on an initial 'scout view' image of the distal portion of the limb to be scanned; the software then selects the appropriate slices longitudinally. The percentage distance from the reference line for the images is marked by the operator in a pre-set program. This also relies heavily on the operator's manual measurement of length from the tibial plateau to the medial malleolus in the lower limb, or from the head of the radius to the styloid process in the upper limb. The reference line must be placed correctly to avoid acquiring images at the growth plates, growth arrest lines or bisphosphonate treatment lines, as these can produce erroneous results (see Fig. 4a and b).

Reference data in healthy children Reference data for children is rather limited but published studies can be used to calculate age-, height- and gender-matched $Z$-scores of the radius or tibia [74]. There is, however, considerable heterogeneity in the literature with regard to the location on a measured limb 


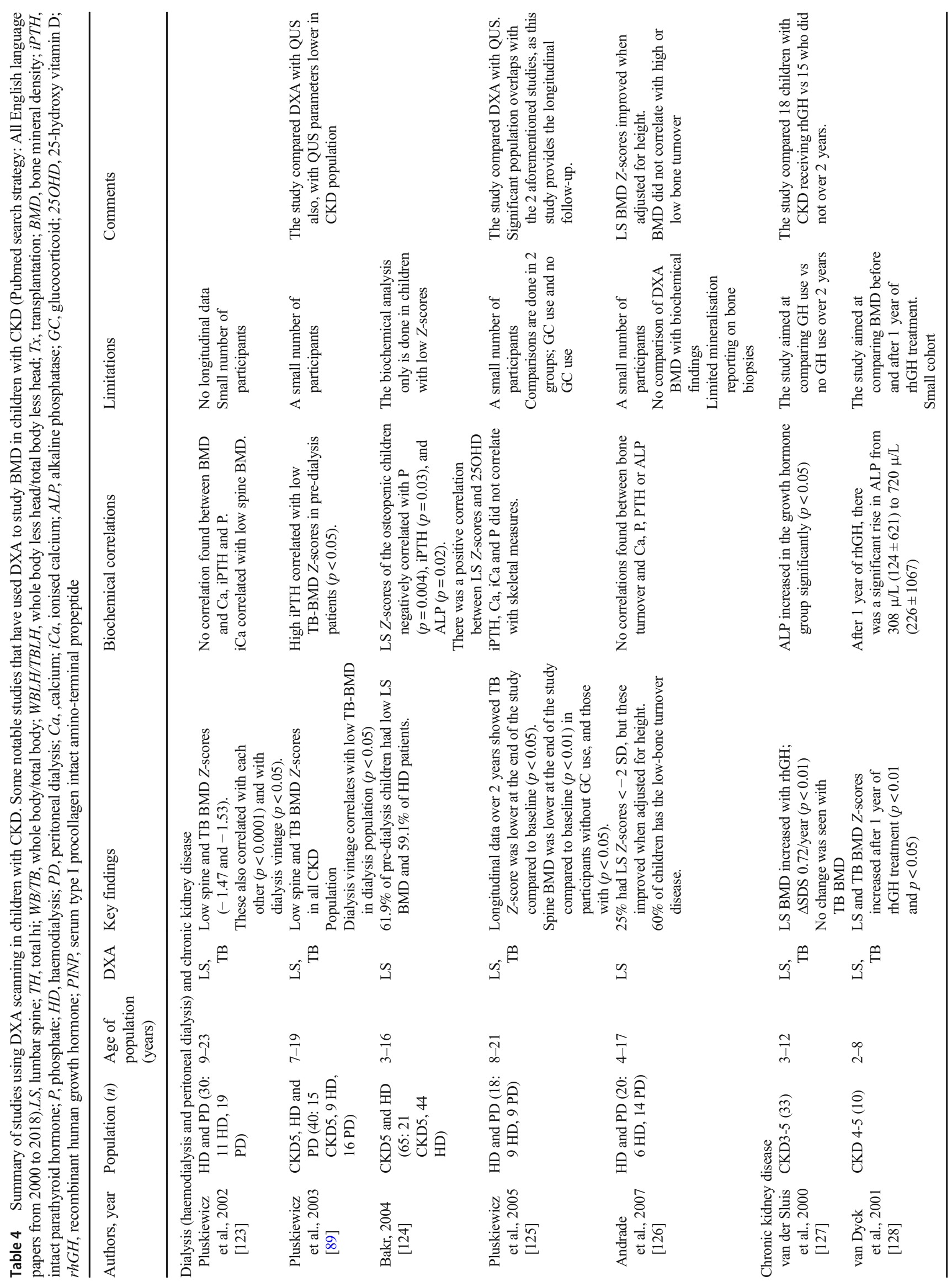




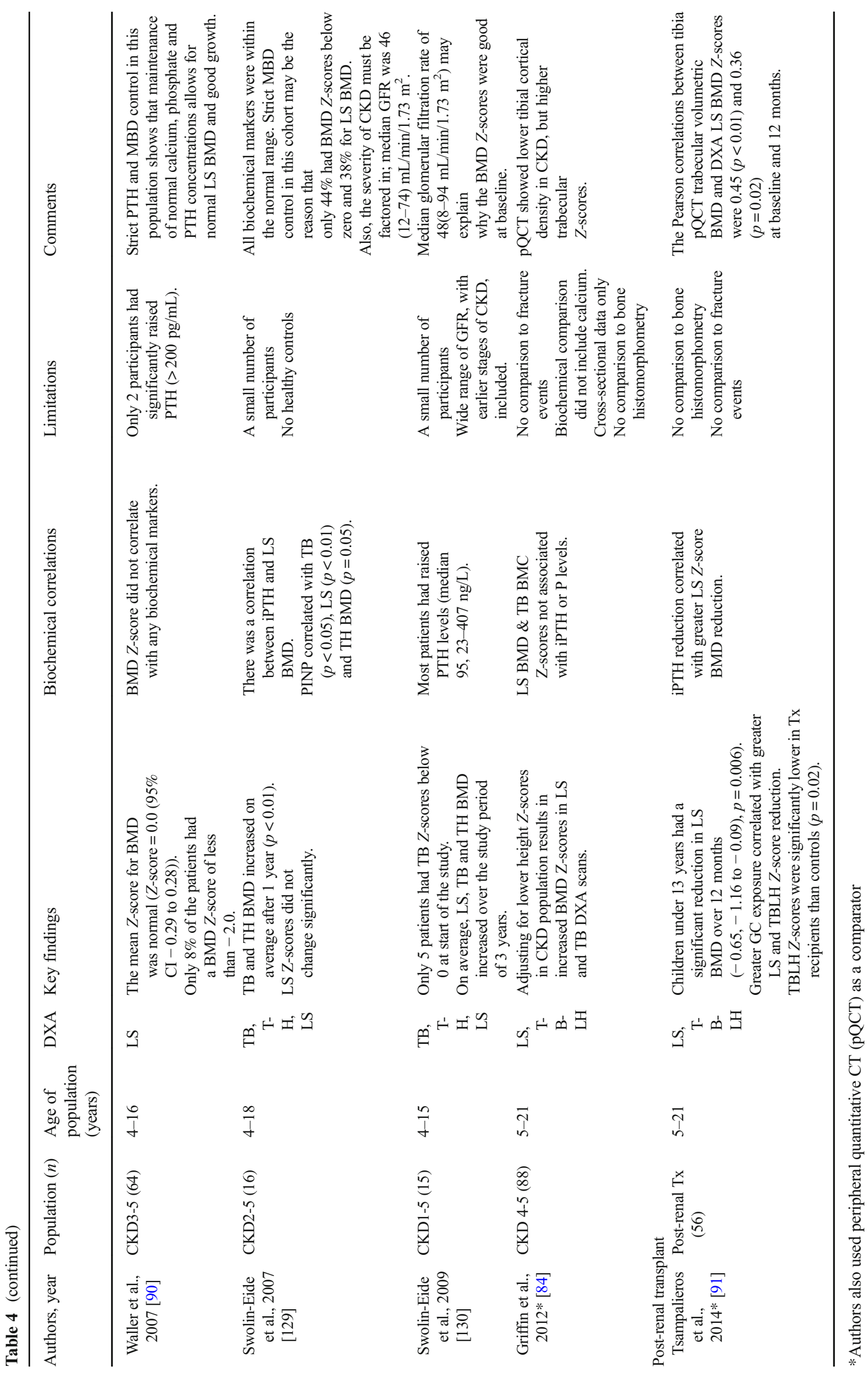


from which the images are obtained [93-98]. This must be taken into account when choosing a reference database

Relative advantages and disadvantages Table 5 lists the main advantages and shortcomings of pQCT in children. pQCT is largely used in research practice only. The main drawback is the marked heterogeneity in the literature in terms of reference line placement, and where the most appropriate slice location is on the tibia or radius for accurate and reproducible assessments. (Anatomical measurement sites reported include 4\%, $20 \%, 30 \%$ and $66 \%$ in the radius and $3 \%, 4 \%, 14 \%, 20 \%$, $38 \%$ and $66 \%$ in the tibia from the distal end of the bone [74, 95]. This heterogeneity means there is a paucity of reference data for age, height and puberty staging for comparison [93-98].

Studies in children with CKD In childhood CKD, pQCT has been used successfully to demonstrate the changes in bone demineralisation seen as the disease progresses (Table 6).

A study comparing 156 children with CKD (stages 2 to 5 including 36 on dialysis) to 831 healthy participants (ages 521 years) using tibial pQCT showed that iPTH levels above the Kidney Disease Outcomes Quality Initiative (KDOQI) recommended target was associated with increased trabecular BMD $Z$-scores $(p<0.01)$, but lower cortical BMD scores $(p<0.01)$. Cortical BMD $Z$-scores were significantly lower in CKD stages 4-5 compared to healthy controls, and the duration of CKD also affected this $(p<0.05)$ [68]. A greater trabecular volumetric BMD was seen in younger participants, the reason for which is not entirely clear. It is postulated that this could be attributed to the anabolic effect of PTH, as this is not seen in other chronic conditions [99]. Lima et al. showed that in 21 patients on peritoneal dialysis, cortical BMD was decreased and this correlated with higher alkaline phosphatase and PTH levels. Trabecular BMD however was higher than in controls, likely due to higher PTH [100]. As described previously, Denburg et al. have shown that per one SD lower baseline cortical BMD $Z$-score, there was a 1.75-fold higher fracture risk (95\% CI $1.15-2.67, p=0.009)$ in children with CKD2-5D [43].

\section{High-resolution $\mathrm{PQCT}$}

High-resolution pQCT (HRpQCT) uses a higher spatial resolution allowing for an even more detailed look at the trabecular bone microarchitecture and enabling measurement of trabecular numbers, thickness and separation [73]. Marques et al. have evaluated adult dialysis patients that underwent bone biopsy and HRpQCT [101] and showed that trabecular number, separation and thickness obtained from HRpQCT and from bone biopsy correlated and that patients with cortical porosity on bone histomorphometry presented lower cortical density at the distal radius. However, HRpQCT could not predict mineralisation abnormalities. Conversely, Pereira et al. showed that bone mineralisation might be assessed by HRpQCT in paediatric dialysis patients [102]. Ramalho et al. obtained DXA imaging of the spine for a trabecular bone score (TBS), and HRpQCT of the radius and tibia in 52 participants who had previously undergone bone biopsy. They showed that TBS reflected trabecular microarchitecture as assessed by bone biopsy, and TBS reflected cortical measures at the tibia as assessed by HRpQCT [103]. Finally, Preka et al. assessed vascular measures and HRpQCT in 32 children aged 10-17 years with CKD stages 2-5 and found an association of calcium and trabecular thickness with mean blood pressure [104].

\section{Magnetic resonance imaging}

Magnetic resonance imaging (MRI) and high-resolution MRI (HR-MRI) in particular have recently been explored as a more detailed way of non-invasively evaluating the bone structure, without the use of ionising radiation [105]. In fact, it is thought that it provides enough detailed information about the standard histomorphometry parameters and microarchitecture to be considered a 'virtual biopsy' by some [106]. It allows for detailed visualisation of both cortical and trabecular compartments and making it possible to see actual three-dimensional views of the architecture. The commonest sites used to obtain images are the distal radius, calcaneus and distal tibia [107, 108]. Adult studies have compared MRI to bone histomorphometry showing good correlation of studied indices across the two modalities $[107,109,110]$. There are no studies in children with CKD.

\section{Bone quantitative ultrasound}

Quantitative ultrasound (QUS) has also been used to assess bone as it is radiation-free, fast, inexpensive and readily available. The measurements are based on the attenuation of the ultrasound wave or speed of sound as it passes through the structure being examined. The penetration depth of the ultrasound waves means that only peripheral sites can be used: commonly, the calcaneus, radius, phalanges or tibia are used. In children, it is currently only used in research as an adjunct to other modalities [111]. Adamczyk et al. assessed seventysix children with CKD and normal renal function who had received glucocorticoid treatment by lumbar and total body DXA as well as phalange QUS. The CKD group had the lowest total body DXA $Z$-scores and the QUS $Z$-scores compared to controls $(p<0.0001)$ [112]. Another study comparing lumbar spine DXA and radius and tibia QUS in 643 participants aged 5-20 years old (412 healthy, 117 with cystic fibrosis and 114 with a body mass index $\mathrm{kg} / \mathrm{m}^{2}$ above 95 th centile) showed a good correlation of the two modalities in healthy 
a

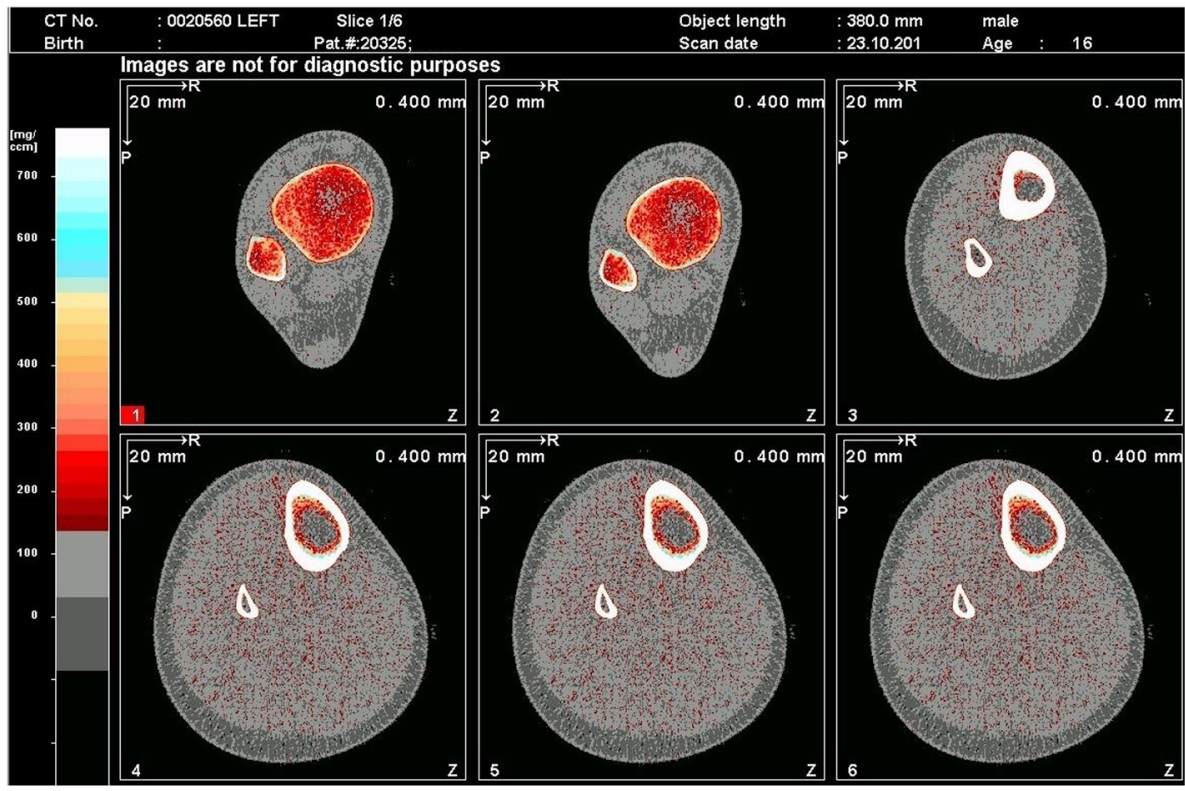

b

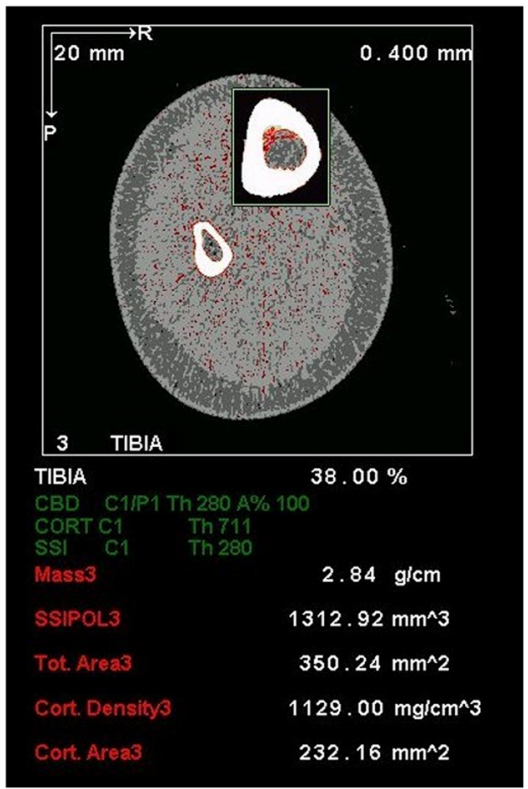

Fig. 4 a pQCT images. This is an example of pQCT imaging of the left tibia of a 16-year-old male with chronic kidney disease. The images have been obtained at 4 different sites along the tibia. The software then proceeds to automatic analysis of the bone parameters. In this example, the

children. However, in children with cystic fibrosis or high BMI, there was a 6-31\% disagreement of measurements. The authors concluded that the two modalities are not yet interchangeable in their use or interpretation [113]. The predictive value of QUS for fracture risk is yet to be explored.

\section{International guidelines on bone assessment in childhood CKD-MBD}

Current management of CKD-MBD is based on keeping calcium, phosphate and $\mathrm{PTH}$ within an optimum range in order to maintain bone turnover, but without increasing the risk of ectopic calcification. This can be done by controlling plasma calcium and phosphate by dietary restrictions, phosphate binders, vitamin $\mathrm{D}$, active vitamin $\mathrm{D}$ analogues and dialysis. These are discussed in the 2006 European Paediatric Dialysis images are from the $3 \%, 4 \%, 38 \%$ and $66 \%$ sites. b This is an example of the analysis of the $38 \%$ site of the left tibia of a 16-year-old male with chronic kidney disease. In this particular analysis, the total mass, total area, cortical area and cortical density have been given

Working Group (EPDWG) prevention and treatment of renal osteodystrophy guidelines, the 2013 National Institute for Health and Clinical Excellence (NICE) management of hyperphosphataemia guidelines [114] and the 2017 KDIGO CKD-MBD guidelines [3].

\section{On biomarkers and bone biopsy in children}

The bone biomarkers studied so far have not been sensitive or specific enough to be translated into an accurate clinical tool to predict bone turnover and mineralisation states. The International Osteoporosis Foundation states that bone turnover markers may be useful in routine clinical practice to predict fracture risk and assess bone mineralisation, but they currently have significant drawbacks such as biological variability and inadequate evidence [10]. It recommends studying PINP as the main
Table 5 Advantages and disadvantages of $\mathrm{pQCT}$ imaging in children. The main advantages and disadvantages of pQCT use in assessing bone in childhood CKD

\begin{tabular}{ll}
\hline Advantages & Disadvantages \\
\hline Low radiation dose $(<1 \mu \mathrm{SV})$ & $\begin{array}{c}\text { Operator dependent on placing reference line } \\
\text { during scanning } \\
\text { Not widely available, as mainly used in } \\
\text { research }\end{array}$ \\
$\begin{array}{l}\text { Other measures acquired: cross-sectional bone area, cortical } \\
\text { thickness }\end{array}$ & $\begin{array}{c}\text { Reference data heterogeneous and not } \\
\text { standardised }\end{array}$ \\
$\begin{array}{l}\text { Volumetric density measured in } \mathrm{g} / \mathrm{cm}^{3} \\
\text { Independent of patient size, so the height and weight of the } \\
\text { patient do not skew results }\end{array}$ & \\
\hline
\end{tabular}



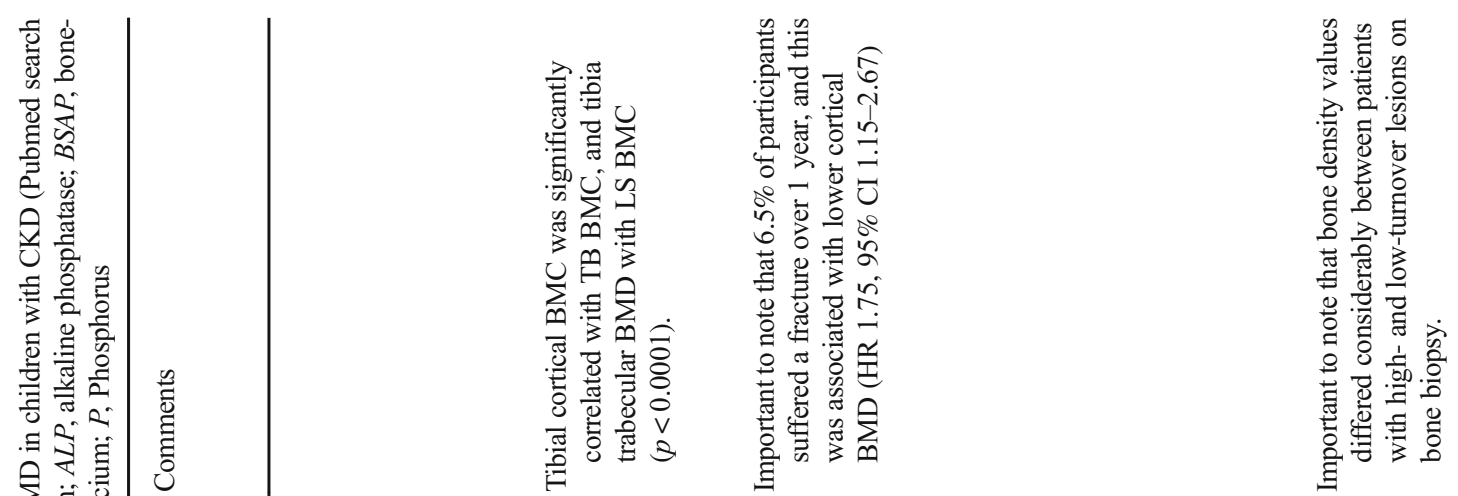

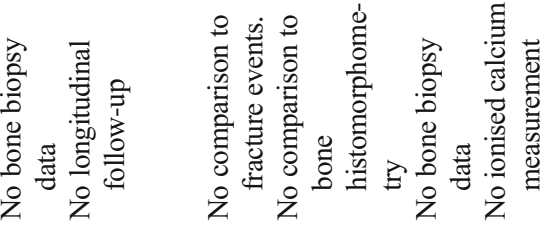

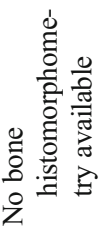

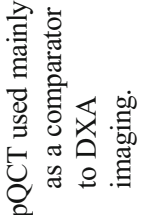
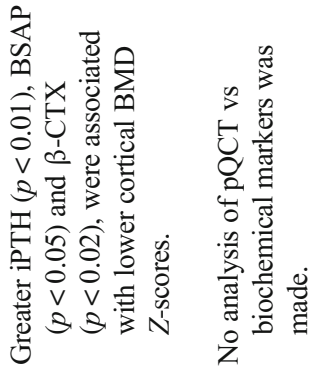

을

总密

栉

至笔

हैं

䨔

응 긍

焉苛

氠吉.

茞

\&

部㟔

$\frac{0}{2}:$

풀

है है

웡

들

3

듕

을

$\Xi \widetilde{\circ}$ 응

일용

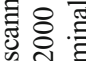

约

ठํ.

品岕

党

능 증

돌을

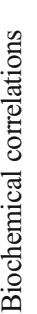

3
0
0
0
0
0

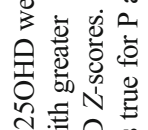

击

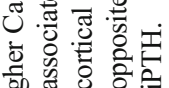

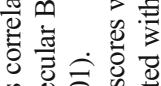

至

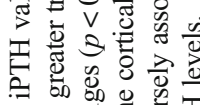

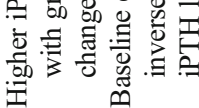

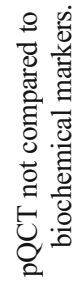

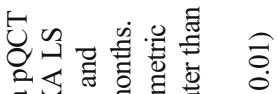

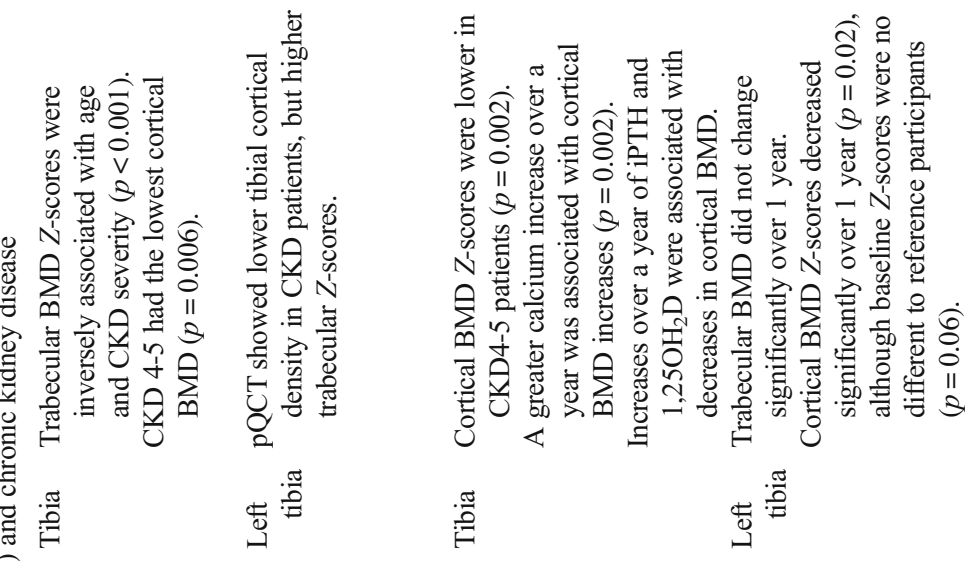

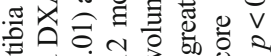

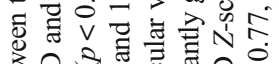

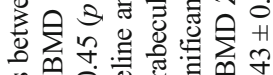

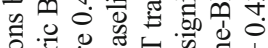

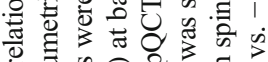

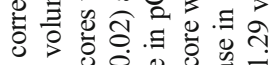
傿

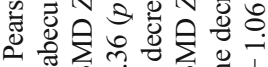

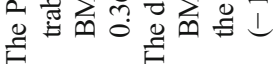
5

的 居

要

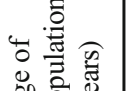

要言总

बु

$\overline{\bar{T}} \quad \bar{i}$

$\bar{i} \quad \bar{i}$

$\overline{\bar{n}} \quad \overline{\mathrm{n}}$

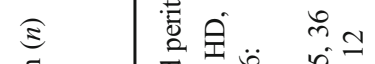

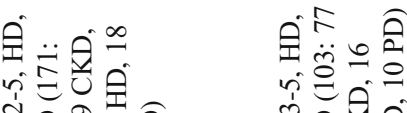

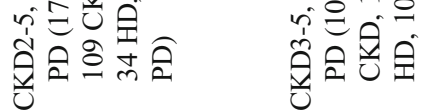

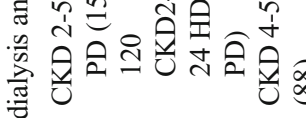

을

言芭守

苞 誉

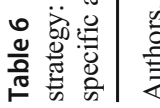

密察

善宁可

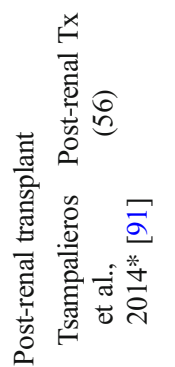


bone formation biomarker and CTX as the main bone resorption biomarker to aid standardisation [10].

Although PTH and BSAP levels have been associated with bone turnover, no biomarker is sufficiently robust to diagnose low, normal and high bone turnover in an individual patient. The 2017 KDIGO guidelines recommend using trends in PTH rather than absolute 'target' values when making decisions as to whether to start or stop treatments to lower PTH. When trends in PTH are inconsistent, a bone biopsy may be considered. The recommendation to perform a bone biopsy is based on the possibility it may affect treatment and the decision to administer antiresorptive therapy. Since this is rarely, if ever, done in children with CKD, the role of bone biopsies remains questionable.

\section{On bone imaging}

The International Society for Clinical Densitometry (ISCD) 2007 and KDIGO 2009 guidelines discouraged routine DXA BMD testing in CKD3-5 since BMD does not predict the type of bone turnover. This is because hyperparathyroidism has generally catabolic effects on the cortical bone with a decrease in cortical volumetric BMD and cortical thickness whereas it exerts anabolic effects on trabecular bone. However, the 2017 KDIGO Guideline on treatment of CKD-MBD [3], based on four prospective cohort studies of DXA BMD and incident fractures in adults with CKD stages 3 a to $5 \mathrm{D}$ [85, 86, $115,116]$, demonstrated that DXA BMD predicted fractures across the spectrum from CKD stages $3 \mathrm{a}$ to $5 \mathrm{D}$ in adults. The guidelines therefore suggest that DXA BMD assessment should be considered if it will lead to additional treatments or therapy recommendations in adults $[3,85,115]$.

For children with CKD, no studies have examined the association between DXA results and fractures, and so the KDIGO 2017 update does not provide specific recommendations for DXA use in children. DXA has been suggested as a potentially useful tool in assessing BMD in children, given that good correlations have been shown between DXA lumbar spine BMD and tibial pQCT measures [91], as well as the correlation between change in tibial cortical BMD and fracture risk [43]. The ISCD in their 2013 Official Positions document also suggests there may yet be a role for DXA in the assessment of BMD in children [76, 77]. Importantly, as children and adolescents with CKD frequently exhibit substantial growth failure, and DXA measures of areal BMD underestimate volumetric BMD in children with short stature [83], DXA results should be adjusted for bone size, consistent with the 2013 ISCD Paediatric Official Positions [76].

\section{Conclusion}

Skeletal abnormalities are prevalent in children with $\mathrm{CKD}$, affecting bone mineralisation from early CKD and manifesting as bone pains, deformities and fractures. The bone disease of childhood CKD can persist after transplantation and even manifest with osteoporosis and fractures in adulthood. Bone imaging, histology and biomarkers are variably used to assess bone disease in CKD, but there are few evidence-based studies to promote their use in routine clinical practice. Current clinical management, as advocated by the KDIGO 2017 guideline, is limited to the measurement and management of trends in serum calcium, phosphate, PTH, vitamin D and alkaline phosphatase, with DXA assessment of BMD if it is likely to influence clinical management.

Funding information ADL is funded by a joint Kidney Research UK (TF_002_20161124) and a Kids Kidney Research Training Fellowship grant $(\mathrm{K} \bar{K} R /$ Paed2017/01). RS holds a Career Development Fellowship with the National Institute for Health Research. This work took place in the Biomedical Research Centre at Great Ormond Street Hospital for Children NHS Foundation Trust and University College London.

\section{Compliance with ethical standards}

Conflict of interest The authors declare that they have no conflict of interest.

Open Access This article is distributed under the terms of the Creative Commons Attribution 4.0 International License (http:// creativecommons.org/licenses/by/4.0/), which permits unrestricted use, distribution, and reproduction in any medium, provided you give appropriate credit to the original author(s) and the source, provide a link to the Creative Commons license, and indicate if changes were made.

\section{References}

1. Moe S, Drueke T, Cunningham J, Goodman W, Martin K, Olgaard K, Ott S, Sprague S, Lameire N, Eknoyan G (2006) Definition, evaluation, and classification of renal osteodystrophy: a position statement from kidney disease: improving global outcomes (KDIGO). Kidney Int 69:1945-1953

2. Wesseling-Perry K, Salusky IB (2013) Phosphate binders, vitamin $\mathrm{D}$ and calcimimetics in the management of chronic kidney disease-mineral bone disorders (CKD-MBD) in children. Pediatric nephrology (Berlin, Germany) 28:617-625

3. Ketteler M, Block GA, Evenepoel P, Fukagawa M, Herzog CA, McCann L, Moe SM, Shroff R, Tonelli MA, Toussaint ND, Vervloet MG, Leonard MB (2018) Diagnosis, evaluation, prevention, and treatment of chronic kidney disease-mineral and bone disorder: synopsis of the kidney disease: improving global outcomes 2017 clinical practice guideline update. Ann Intern Med 168:422-430

4. Fang Y, Ginsberg C, Sugatani T, Monier-Faugere M-C, Malluche H, Hruska KA (2014) Early chronic kidney disease-mineral bone disorder stimulates vascular calcification. Kidney Int 85:142-150

5. Ketteler M, Block GA, Evenepoel P, Fukagawa M, Herzog CA, McCann L, Moe SM, Shroff R, Tonelli MA, Toussaint ND, 
Vervloet MG, Leonard MB Executive summary of the 2017 KDIGO chronic kidney\&\#xa0;disease\&\#x2013;mineral and bone disorder (CKD-MBD) guideline update: what\&\#x2019;s changed and why it matters. Kidney Int 92:26-36

6. Ott SM (2008) Histomorphometric measurements of bone turnover, mineralization, and volume. Clin J Am Soc Nephrol 3(Suppl 3):S151-S156

7. Rauch F, Schoenau E (2001) Changes in bone density during childhood and adolescence: an approach based on bone's biological organization. J Bone Miner Res 16:597-604

8. Kini U, Nandeesh B (2012) Physiology of bone formation, remodeling and metabolism. In: Fogelman I, Gnanasegaran G, van der Wall HE (eds) Radionuclide and hybrid bone imaging. Springer, pp 29-57

9. Manolagas SC (2000) Birth and death of bone cells: basic regulatory mechanisms and implications for the pathogenesis and treatment of osteoporosis. Endocr Rev 21:115-137

10. Vasikaran S, Eastell R, Bruyere O, Foldes AJ, Garnero P, Griesmacher A, McClung M, Morris HA, Silverman S, Trenti T, Wahl DA, Cooper C, Kanis JA (2011) Markers of bone turnover for the prediction of fracture risk and monitoring of osteoporosis treatment: a need for international reference standards. Osteoporos Int 22:391-420

11. Katsimbri P (2017) The biology of normal bone remodelling. Eur J Cancer Care (Engl) 26

12. Stagi S, Cavalli L, Iurato C, Seminara S, Brandi ML, de Martino M (2013) Bone metabolism in children and adolescents: main characteristics of the determinants of peak bone mass. Clinical Cases in Mineral and Bone Metabolism 10:172-179

13. Orimo $\mathrm{H}$ (2010) The mechanism of mineralization and the role of alkaline phosphatase in health and disease. J Nippon Med Sch 77: 4-12

14. Kuizon BD, Salusky IB (1999) Growth retardation in children with chronic renal failure. J Bone Miner Res 14:1680-1690

15. Bacchetta J, Harambat J, Cochat P, Salusky IB, Wesseling-Perry K (2012) The consequences of chronic kidney disease on bone metabolism and growth in children. Nephrol Dial Transplant 27: 3063-3071

16. Frost HM (2002) Emerging views about "osteoporosis", bone health, strength, fragility, and their determinants. J Bone Miner Metab 20:319-325

17. Clarke B (2008) Normal bone anatomy and physiology. Clin J Am Soc Nephrol Suppl 3:S131-S139

18. Seeman E (2003) The structural and biomechanical basis of the gain and loss of bone strength in women and men. Endocrinol Metab Clin N Am 32:25-38

19. Weaver CM, Gordon CM, Janz KF, Kalkwarf HJ, Lappe JM, Lewis R, O'Karma M, Wallace TC, Zemel BS (2016) The National Osteoporosis Foundation's position statement on peak bone mass development and lifestyle factors: a systematic review and implementation recommendations. Osteoporos Int 27:12811386

20. Ferrari SL, Chevalley T, Bonjour JP, Rizzoli R (2006) Childhood fractures are associated with decreased bone mass gain during puberty: an early marker of persistent bone fragility? J Bone Miner Res 21:501-507

21. Whiting SJ, Vatanparast H, Baxter-Jones A, Faulkner RA, Mirwald R, Bailey DA (2004) Factors that affect bone mineral accrual in the adolescent growth spurt. J Nutr 134:696s-700s

22. Baxter-Jones AD, Faulkner RA, Forwood MR, Mirwald RL, Bailey DA (2011) Bone mineral accrual from 8 to 30 years of age: an estimation of peak bone mass. J Bone Miner Res 26: 1729-1739

23. Recker RR, Davies KM, Hinders SM, Heaney RP, Stegman MR, Kimmel DB (1992) Bone gain in young adult women. Jama 268: 2403-2408
24. Lin YC, Lyle RM, Weaver CM, McCabe LD, McCabe GP, Johnston CC, Teegarden D (2003) Peak spine and femoral neck bone mass in young women. Bone 32:546-553

25. Matkovic V, Heaney RP (1992) Calcium balance during human growth: evidence for threshold behavior. Am J Clin Nutr 55:992996

26. Chan GM, Hoffman K, McMurry M (1995) Effects of dairy products on bone and body composition in pubertal girls. J Pediatr 126: 551-556

27. Johnston CC Jr, Miller JZ, Slemenda CW, Reister TK, Hui S, Christian JC, Peacock M (1992) Calcium supplementation and increases in bone mineral density in children. N Engl J Med 327:82-87

28. Bonjour JP, Carrie AL, Ferrari S, Clavien H, Slosman D, Theintz G, Rizzoli R (1997) Calcium-enriched foods and bone mass growth in prepubertal girls: a randomized, double-blind, placebo-controlled trial. J Clin Investig 99:1287-1294

29. Cadogan J, Eastell R, Jones N, Barker ME (1997) Milk intake and bone mineral acquisition in adolescent girls: randomised, controlled intervention trial. BMJ [Br Med J] 315:1255-1260

30. Matkovic V, Goel PK, Badenhop-Stevens NE, Landoll JD, Li B, Ilich JZ, Skugor M, Nagode LA, Mobley SL, Ha EJ, Hangartner TN, Clairmont A (2005) Calcium supplementation and bone mineral density in females from childhood to young adulthood: a randomized controlled trial. Am J Clin Nutr 81:175-188

31. Abrams SA, Esteban NV, Vieira NE, Yergey AL (1991) Dual tracer stable isotopic assessment of calcium absorption and endogenous fecal excretion in low birth weight infants. Pediatr Res 29: 615-618

32. Abrams SA (1999) Using stable isotopes to assess mineral absorption and utilization by children. Am J Clin Nutr 70:955-964

33. Borzych D, Rees L, Ha IS, Chua A, Valles PG, Lipka M, Zambrano P, Ahlenstiel T, Bakkaloglu SA, Spizzirri AP, Lopez L, Ozaltin F, Printza N, Hari P, Klaus G, Bak M, Vogel A, Ariceta G, Yap HK, Warady BA, Schaefer F (2010) The bone and mineral disorder of children undergoing chronic peritoneal dialysis. Kidney Int 78:1295-1304

34. Wan M, Smith C, Shah V, Gullet A, Wells D, Rees L, Shroff R (2013) Fibroblast growth factor 23 and soluble klotho in children with chronic kidney disease. Nephrol Dial Transplant 28:153-161

35. Portale AA, Wolf M, Juppner H, Messinger S, Kumar J, Wesseling-Perry K, Schwartz GJ, Furth SL, Warady BA, Salusky IB (2014) Disordered FGF23 and mineral metabolism in children with CKD. Clin J Am Soc Nephrol 9:344-353

36. Levin A, Bakris GL, Molitch M, Smulders M, Tian J, Williams LA, Andress DL (2007) Prevalence of abnormal serum vitamin D, PTH, calcium, and phosphorus in patients with chronic kidney disease: results of the study to evaluate early kidney disease. Kidney Int 71:31-38

37. Hruska KA, Seifert M, Sugatani T (2015) Pathophysiology of the chronic kidney disease-mineral bone disorder. Curr Opin Nephrol Hypertens 24:303-309

38. Denburg MR, Kumar J, Jemielita T, Brooks ER, Skversky A, Portale AA, Salusky IB, Warady BA, Furth SL, Leonard MB (2016) Fracture burden and risk factors in childhood CKD: results from the CKiD cohort study. J Am Soc Nephrol 27:543-550

39. Oh J, Wunsch R, Turzer M, Bahner M, Raggi P, Querfeld U, Mehls O, Schaefer F (2002) Advanced coronary and carotid arteriopathy in young adults with childhood-onset chronic renal failure. Circulation 106:100-105

40. Shroff RC, Donald AE, Hiorns MP, Watson A, Feather S, Milford D, Ellins EA, Storry C, Ridout D, Deanfield J, Rees L (2007) Mineral metabolism and vascular damage in children on dialysis. J Am Soc Nephrol 18:2996-3003

41. Carrillo-Lopez N, Panizo S, Alonso-Montes C, Roman-Garcia P, Rodriguez I, Martinez-Salgado C, Dusso AS, Naves M, Cannata- 
Andia JB (2016) Direct inhibition of osteoblastic Wnt pathway by fibroblast growth factor 23 contributes to bone loss in chronic kidney disease. Kidney Int 90:77-89

42. McNerny EMB, Nickolas TL (2017) Bone quality in chronic kidney disease: definitions and diagnostics. Curr Osteoporos Rep 15: 207-213

43. Denburg MR, Tsampalieros AK, de Boer IH, Shults J, Kalkwarf HJ, Zemel BS, Foerster D, Stokes D, Leonard MB (2013) Mineral metabolism and cortical volumetric bone mineral density in childhood chronic kidney disease. J Clin Endocrinol Metab 98:1930 1938

44. Wesseling-Perry K (2015) Defective skeletal mineralization in pediatric CKD. Curr Osteoporos Rep 13:98-105

45. Jarvinen TL, Sievanen H, Jokihaara J, Einhorn TA (2005) Revival of bone strength: the bottom line. J Bone Miner Res 20:717-720

46. Gabel L, Macdonald HM, McKay HA (2017) Sex differences and growth-related adaptations in bone microarchitecture, geometry, density, and strength from childhood to early adulthood: a mixed longitudinal HR-pQCT study. J Bone Miner Res 32:250-263

47. Groothoff JW, Gruppen MP, Offringa M, Hutten J, Lilien MR, Van De Kar NJ, Wolff ED, Davin JC, Heymans HS (2002) Mortality and causes of death of end-stage renal disease in children: a Dutch cohort study. Kidney Int 61:621-629

48. Haffner D, Schaefer F, Nissel R, Wuhl E, Tonshoff B, Mehls O (2000) Effect of growth hormone treatment on the adult height of children with chronic renal failure. German Study Group for Growth Hormone Treatment in Chronic Renal Failure. N Engl J Med 343:923-930

49. Jadoul M, Albert JM, Akiba T, Akizawa T, Arab L, BraggGresham JL, Mason N, Prutz KG, Young EW, Pisoni RL (2006) Incidence and risk factors for hip or other bone fractures among hemodialysis patients in the Dialysis Outcomes and Practice Patterns Study. Kidney Int 70:1358-1366

50. Bonthuis M, Busutti M, van Stralen KJ, Jager KJ, Baiko S, Bakkaloğlu S, Battelino N, Gaydarova M, Gianoglio B, Parvex P, Gomes C, Heaf JG, Podracka L, Kuzmanovska D, Molchanova MS, Pankratenko TE, Papachristou F, Reusz G, Sanahuja MJ, Shroff R, Groothoff JW, Schaefer F, Verrina E (2015) Mineral metabolism in European children living with a renal transplant: a European Society for Paediatric Nephrology/European Renal Association-European Dialysis and Transplant Association Registry Study. Clin J Am Soc Nephrol 10:767-775

51. Helenius I, Remes V, Salminen S, Valta H, Mäkitie O, Holmberg C, Palmu P, Tervahartiala P, Sarna S, Helenius M, Peltonen J, Jalanko H (2006) Incidence and predictors of fractures in children after solid organ transplantation: a 5-year prospective, populationbased study

52. Groothoff JW, Offringa M, Van Eck-Smit BL, Gruppen MP, Van De Kar NJ, Wolff ED, Lilien MR, Davin JC, Heymans HS, Dekker FW (2003) Severe bone disease and low bone mineral density after juvenile renal failure. Kidney Int 63:266-275

53. Alem AM, Sherrard DJ, Gillen DL, Weiss NS, Beresford SA, Heckbert SR, Wong C, Stehman-Breen C (2000) Increased risk of hip fracture among patients with end-stage renal disease. Kidney Int 58:396-399

54. Coco M, Rush H (2000) Increased incidence of hip fractures in dialysis patients with low serum parathyroid hormone. Am J Kidney Dis 36:1115-1121

55. Tentori F, McCullough K, Kilpatrick RD, Bradbury BD, Robinson BM, Kerr PG, Pisoni RL (2013) Response to high rates of death and hospitalization follow bone fracture among hemodialysis patients. Kidney Int 85:166-173

56. (2009) KDIGO clinical practice guideline for the diagnosis, evaluation, prevention, and treatment of Chronic Kidney DiseaseMineral and Bone Disorder (CKD-MBD). Kidney Int Suppl:S1130
57. Torres PU, Bover J, Mazzaferro S, de Vernejoul MC, Cohen-Solal M (2014) When, how, and why a bone biopsy should be performed in patients with chronic kidney disease. Semin Nephrol 34:612-625

58. Rees L (2008) What parathyroid hormone levels should we aim for in children with stage 5 chronic kidney disease; what is the evidence? Pediatric nephrology (Berlin, Germany) 23:179-184

59. Delanaye P, Souberbielle JC, Lafage-Proust MH, Jean G, Cavalier E (2014) Can we use circulating biomarkers to monitor bone turnover in CKD haemodialysis patients? Hypotheses and facts. Nephrol Dial Transplant 29:997-1004

60. Fischer DC, Mischek A, Wolf S, Rahn A, Salweski B, Kundt G, Haffner D (2012) Paediatric reference values for the C-terminal fragment of fibroblast-growth factor-23, sclerostin, bone-specific alkaline phosphatase and isoform $5 \mathrm{~b}$ of tartrate-resistant acid phosphatase. Ann Clin Biochem 49:546-553

61. Bonewald LF (2011) The amazing osteocyte. J Bone Miner Res 26:229-238

62. Bakkaloglu SA, Wesseling-Perry K, Pereira RC, Gales B, Wang HJ, Elashoff RM, Salusky IB (2010) Value of the new bone classification system in pediatric renal osteodystrophy. Clin J Am Soc Nephrol 5:1860-1866

63. Wesseling-Perry K, Pereira RC, Tseng CH, Elashoff R, Zaritsky JJ, Yadin O, Sahney S, Gales B, Juppner H, Salusky IB (2012) Early skeletal and biochemical alterations in pediatric chronic kidney disease. Clin J Am Soc Nephrol 7:146-152

64. Barreto FC, Barreto DV, Moysés RMA, Neves KR, Canziani MEF, Draibe SA, Jorgetti V, Carvalho AB (2008) K/DOQIrecommended intact $\mathrm{PTH}$ levels do not prevent low-turnover bone disease in hemodialysis patients. Kidney Int 73:771-777

65. Salusky IB, Ramirez JA, Oppenheim W, Gales B, Segre GV, Goodman WG (1994) Biochemical markers of renal osteodystrophy in pediatric patients undergoing CAPD/CCPD. Kidney Int 45:253-258

66. Waller S, Shroff R, Freemont AJ, Rees L (2008) Bone histomorphometry in children prior to commencing renal replacement therapy. Pediatr Nephrol 23:1523-1529

67. Doyon A, Fischer DC, Bayazit AK, Canpolat N, Duzova A, Sozeri B, Bacchetta J, Balat A, Buscher A, Candan C, Cakar N, Donmez O, Dusek J, Heckel M, Klaus G, Mir S, Ozcelik G, Sever L, Shroff R, Vidal E, Wuhl E, Gondan M, Melk A, Querfeld U, Haffner D, Schaefer F (2015) Markers of bone metabolism are affected by renal function and growth hormone therapy in children with chronic kidney disease. PLoS One 10:e0113482

68. Wetzsteon RJ, Kalkwarf HJ, Shults J, Zemel BS, Foster BJ, Griffin L, Strife CF, Foerster DL, Jean-Pierre DK, Leonard MB (2011) Volumetric bone mineral density and bone structure in childhood chronic kidney disease. J Bone Miner Res 26:2235-2244

69. Sprague SM, Bellorin-Font E, Jorgetti V, Carvalho AB, Malluche HH, Ferreira A, D'Haese PC, Drueke TB, Du H, Manley T, Rojas E, Moe SM (2016) Diagnostic accuracy of bone turnover markers and bone histology in patients with CKD treated by dialysis. Am J Kidney Dis 67:559-566

70. Behets GJ, Spasovski G, Sterling LR, Goodman WG, Spiegel DM, De Broe ME, D'Haese PC (2015) Bone histomorphometry before and after long-term treatment with cinacalcet in dialysis patients with secondary hyperparathyroidism. Kidney Int 87: 846-856

71. Glendenning P (2011) Markers of bone turnover for the prediction of fracture risk and monitoring of osteoporosis treatment: a need for international reference standards: osteoporos int 2011;22:391420. Clin Biochem Rev 32:45-47

72. Wasserman H, O'Donnell JM, Gordon CM (2017) Use of dual energy X-ray absorptiometry in pediatric patients. Bone 104:84 90 
73. Crabtree N, Ward K (2015) Bone densitometry: current status and future perspective. Endocr Dev 28:72-83

74. Adams JE, Engelke K, Zemel BS, Ward KA (2014) Quantitative computer tomography in children and adolescents: the 2013 ISCD pediatric official positions. J Clin Densitom 17:258-274

75. Messina C, Lastella G, Sorce S, Piodi LP, Rodari G, Giavoli C, Marchelli D, Guglielmi G, Ulivieri FM (2018) Pediatric dualenergy X-ray absorptiometry in clinical practice: what the clinicians need to know. Eur J Radiol 105:153-161

76. Crabtree NJ, Arabi A, Bachrach LK, Fewtrell M, El-Hajj Fuleihan G, Kecskemethy HH, Jaworski M, Gordon CM (2014) Dualenergy X-ray absorptiometry interpretation and reporting in children and adolescents: the revised 2013 ISCD pediatric official positions. J Clin Densitom 17:225-242

77. Gordon CM, Leonard MB, Zemel BS (2014) 2013 pediatric position development conference: executive summary and reflections. J Clin Densitom 17:219-224

78. Crabtree NJ, Shaw NJ, Bishop NJ, Adams JE, Mughal MZ, Arundel P, Fewtrell MS, Ahmed SF, Treadgold LA, Hogler W, Bebbington NA, Ward KA (2017) Amalgamated reference data for size-adjusted bone densitometry measurements in 3598 children and young adults-the ALPHABET study. J Bone Miner Res $32: 172-180$

79. Kalkwarf HJ, Zemel BS, Gilsanz V, Lappe JM, Horlick M, Oberfield S, Mahboubi S, Fan B, Frederick MM, Winer K, Shepherd JA (2007) The bone mineral density in childhood study: bone mineral content and density according to age, sex, and race. J Clin Endocrinol Metab 92:2087-2099

80. Ward KA, Ashby RL, Roberts SA, Adams JE, Zulf Mughal M (2007) UK reference data for the hologic QDR discovery dualenergy $\mathrm{x}$ ray absorptiometry scanner in healthy children and young adults aged 6-17 years. Arch Dis Child 92:53-59

81. Zemel BS, Kalkwarf HJ, Gilsanz V, Lappe JM, Oberfield S, Shepherd JA, Frederick MM, Huang X, Lu M, Mahboubi S, Hangartner T, Winer KK (2011) Revised reference curves for bone mineral content and areal bone mineral density according to age and sex for black and non-black children: results of the bone mineral density in childhood study. J Clin Endocrinol Metab 96:3160-3169

82. Chastin SF, Mandrichenko O, Skelton DA (2014) The frequency of osteogenic activities and the pattern of intermittence between periods of physical activity and sedentary behaviour affects bone mineral content: the cross-sectional NHANES study. BMC Public Health 14:4-4

83. Zemel BS, Leonard MB, Kelly A, Lappe JM, Gilsanz V, Oberfield S, Mahboubi S, Shepherd JA, Hangartner TN, Frederick MM, Winer KK, Kalkwarf HJ (2010) Height adjustment in assessing dual energy x-ray absorptiometry measurements of bone mass and density in children. J Clin Endocrinol Metab 95:1265-1273

84. Griffin LM, Kalkwarf HJ, Zemel BS, Shults J, Wetzsteon RJ, Strife CF, Leonard MB (2012) Assessment of dual-energy X-ray absorptiometry measures of bone health in pediatric chronic kidney disease. Pediatr Nephrol 27:1139-1148

85. Yenchek RH, Ix JH, Shlipak MG, Bauer DC, Rianon NJ, Kritchevsky SB, Harris TB, Newman AB, Cauley JA, Fried LF (2012) Bone mineral density and fracture risk in older individuals with CKD. Clin J Am Soc Nephrol 7:1130-1136

86. Iimori S, Mori Y, Akita W, Kuyama T, Takada S, Asai T, Kuwahara M, Sasaki S, Tsukamoto Y (2012) Diagnostic usefulness of bone mineral density and biochemical markers of bone turnover in predicting fracture in CKD stage 5D patients-a singlecenter cohort study. Nephrol Dial Transplant 27:345-351

87. Nickolas TL, McMahon DJ, Shane E (2006) Relationship between moderate to severe kidney disease and hip fracture in the United States. J Am Soc Nephrol 17:3223-3232
88. Nickolas TL, Cremers S, Zhang A, Thomas V, Stein E, Cohen A, Chauncey R, Nikkel L, Yin MT, Liu XS, Boutroy S, Staron RB, Leonard MB, McMahon DJ, Dworakowski E, Shane E (2011) Discriminants of prevalent fractures in chronic kidney disease. $\mathrm{J}$ Am Soc Nephrol 22:1560-1572

89. Pluskiewicz W, Adamczyk P, Drozdzowska B, Szprynger K, Szczepanska M, Halaba Z, Karasek D (2003) Skeletal status in children and adolescents with chronic renal failure before onset of dialysis or on dialysis. Osteoporos Int 14:283-288

90. Waller S, Ridout D, Rees L (2007) Bone mineral density in children with chronic renal failure. Pediatr Nephrol 22:121-127

91. Tsampalieros A, Griffin L, Terpstra AM, Kalkwarf HJ, Shults J, Foster BJ, Zemel BS, Foerster DL, Leonard MB (2014) Changes in DXA and quantitative CT measures of musculoskeletal outcomes following pediatric renal transplantation. Am J Transplant 14:124-132

92. Stagi S, Cavalli L, Cavalli T, de Martino M, Brandi ML (2016) Peripheral quantitative computed tomography (pQCT) for the assessment of bone strength in most of bone affecting conditions in developmental age: a review. Ital J Pediatr 42:88-88

93. Neu CM, Manz F, Rauch F, Merkel A, Schoenau E (2001) Bone densities and bone size at the distal radius in healthy children and adolescents: a study using peripheral quantitative computed tomography. Bone 28:227-232

94. Binkley TL, Specker BL, Wittig TA (2002) Centile curves for bone densitometry measurements in healthy males and females ages 5-22 yr. J Clin Densitom 5:343-353

95. Duff WRD, Björkman KM, Kawalilak CE, Kehrig AM, Wiebe S, Kontulainen S (2017) Precision of pQCT-measured total, trabecular and cortical bone area, content, density and estimated bone strength in children. J Musculoskelet Neuronal Interact 17:59-68

96. Roggen I, Roelants M, Sioen I, Vandewalle S, De Henauw S, Goemaere S, Kaufman JM, De Schepper J (2015) Pediatric reference values for tibial trabecular bone mineral density and bone geometry parameters using peripheral quantitative computed tomography. Calcif Tissue Int 96:527-533

97. Leonard MB, Elmi A, Mostoufi-Moab S, Shults J, Burnham JM, Thayu M, Kibe L, Wetzsteon RJ, Zemel BS (2010) Effects of sex, race, and puberty on cortical bone and the functional muscle bone unit in children, adolescents, and young adults. J Clin Endocrinol Metab 95:1681-1689

98. Moyer-Mileur LJ, Quick JL, Murray MA (2008) Peripheral quantitative computed tomography of the tibia: pediatric reference values. J Clin Densitom 11:283-294

99. Parfitt AM (1998) A structural approach to renal bone disease. J Bone Miner Res 13:1213-1220

100. Lima EM, Goodman WG, Kuizon BD, Gales B, Emerick A, Goldin J, Salusky IB (2003) Bone density measurements in pediatric patients with renal osteodystrophy. Pediatr Nephrol 18:554 559

101. Marques ID, Araujo MJ, Graciolli FG, Reis LM, Pereira RM, Custodio MR, Jorgetti V, Elias RM, David-Neto E, Moyses RM (2017) Biopsy vs. peripheral computed tomography to assess bone disease in CKD patients on dialysis: differences and similarities. Osteoporos Int 28:1675-1683

102. Pereira RC, Bischoff DS, Yamaguchi D, Salusky IB, WesselingPerry K (2016) Micro-CT in the assessment of pediatric renal osteodystrophy by bone histomorphometry. Clin J Am Soc Nephrol 11:481-487

103. Ramalho J, Marques IDB, Hans D, Dempster D, Zhou H, Patel P, Pereira RMR, Jorgetti V, Moyses RMA, Nickolas TL (2018) The trabecular bone score: relationships with trabecular and cortical microarchitecture measured by HR-pQCT and histomorphometry in patients with chronic kidney disease. Bone 116:215-220 
104. Preka E, Ranchin B, Doyon A, Vierge M, Ginhoux T, Kassai B, Bacchetta J (2018) The interplay between bone and vessels in pediatric CKD: lessons from a single-center study. Pediatr Nephrol

105. Sharma AK, Masterson R, Holt SG, Toussaint ND (2016) Emerging role of high-resolution imaging in the detection of renal osteodystrophy. Nephrology (Carlton) 21:801-811

106. Leonard MB (2007) A structural approach to the assessment of fracture risk in children and adolescents with chronic kidney disease. Pediatr Nephrol 22:1815-1824

107. Wehrli FW, Leonard MB, Saha PK, Gomberg BR (2004) Quantitative high-resolution magnetic resonance imaging reveals structural implications of renal osteodystrophy on trabecular and cortical bone. J Magn Reson Imaging 20:83-89

108. Gomberg BR, Wehrli FW, Vasilic B, Weening RH, Saha PK, Song HK, Wright AC (2004) Reproducibility and error sources of micro-MRI-based trabecular bone structural parameters of the distal radius and tibia. Bone 35:266-276

109. Link TM, Saborowski KK, Kempkes M, Kosch M, Newitt D, Lu Y, Waldt S, Majumdar S (2002) Changes in calcaneal trabecular bone structure assessed with high-resolution MR imaging in patients with kidney transplantation. Osteoporos Int 13:119-129

110. Sharma AK, Toussaint ND, Elder GJ, Masterson R, Holt SG, Robertson PL, Ebeling PR, Baldock P, Miller RC, Rajapakse CS (2018) Magnetic resonance imaging based assessment of bone microstructure as a non-invasive alternative to histomorphometry in patients with chronic kidney disease. Bone 114:14-21

111. Stagi S, Cavalli L, Iurato C, Seminara S, Brandi ML, de Martino M (2013) Bone health in children and adolescents: the available imaging techniques. Clin Cases Miner Bone Metab 10:166-171
112. Adamczyk P, Szczepanska M, Pluskiewicz W (2018) Skeletal status assessment by quantitative ultrasound and bone densitometry in children with different renal conditions. Osteoporos Int

113. Williams JE, Wilson CM, Biassoni L, Suri R, Fewtrell MS (2012) Dual energy $\mathrm{x}$-ray absorptiometry and quantitative ultrasound are not interchangeable in diagnosing abnormal bones. Arch Dis Child 97:822-824

114. Dasgupta I, Shroff R, Bennett-Jones D, McVeigh G (2013) Management of hyperphosphataemia in chronic kidney disease: summary of National Institute for Health and Clinical Excellence (NICE) guideline. Nephron Clin Pract 124:1-9

115. Naylor KL, Garg AX, Zou G, Langsetmo L, Leslie WD, Fraser LA, Adachi JD, Morin S, Goltzman D, Lentle B, Jackson SA, Josse RG, Jamal SA (2015) Comparison of fracture risk prediction among individuals with reduced and normal kidney function. Clin J Am Soc Nephrol 10:646-653

116. West SL, Lok CE, Langsetmo L, Cheung AM, Szabo E, Pearce D, Fusaro M, Wald R, Weinstein J, Jamal SA (2015) Bone mineral density predicts fractures in chronic kidney disease. J Bone Miner Res 30:913-919

117. Charoenphandhu N, Wongdee K, Krishnamra N (2010) Is prolactin the cardinal calciotropic maternal hormone? Trends Endocrinol Metab 21:395-401

Publisher's note Springer Nature remains neutral with regard to jurisdictional claims in published maps and institutional affiliations. 